\title{
(Dis)harmony, the Head-Proximate Filter, and linkers ${ }^{\mathrm{I}}$
}

\author{
JOY PHILIP \\ University College London \\ (Received 23 September 20I0; revised 23 January 20I2)
}

This paper presents a notion of harmonic word order that leads to a new generalisation over the presence or absence of disharmony cross-linguistically: for linkers - syntactically independent, semantically vacuous heads marking a relationship - disharmony is ungrammatical, while for any other head disharmony is simply dispreferred. Harmony is defined here by the interaction of three independently motivated word order constraints operating over the base-generated structure: linear proximity between a superordinate lexical head and the head of its dependent, uniformity in direction of headedness, and the preference for clausal dependents to follow their head. It is proposed that disharmony occurs where either a lexical head or a head bearing syntactic features encoding semantics has an ordering rule of its own. These proposals are shown to be empirically superior to the Final-Over-Final Constraint (Holmberg 2000, Biberauer, Holmberg \& Roberts 2007 and subsequent work), in terms of both what is permitted and what is disallowed.

\section{INTRODUCTION}

The presence of harmonic, or optimal, word order constraints presents a point of interest to both generative grammarians and typologists. In particular, much attention has been paid to directionality of headedness, with the consistently head-initial and consistently head-final orders - shown here in (Ia) and ( $\mathrm{Ib}$ ) respectively - considered harmonic, while those displaying mixed headedness, as in (Ic, d), are regarded as disharmonic:

(I) Harmonic orders

(a) Initial-over-initial

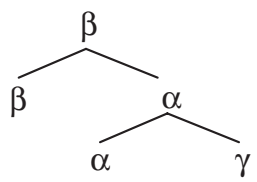

(b) Final-over-final

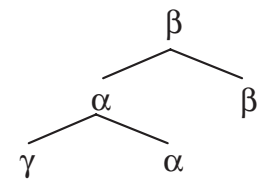

[I] My thanks to Ad Neeleman for detailed discussions and feedback. This paper has also benefited from comments from three anonymous $J L$ referees and the editor, Caroline Heycock. My thanks are further due to participants at presentations given at UCL, Newcastle University and the LAGB Annual Meeting 20I0. Many thanks to Dennis Philip, Daniel Philipose and Leelamma Philipose for Malayalam judgments, to Misako Tanaka and Reiko Vermeulen for Japanese judgments, to Aïcha Mahamat, Hadja Habi Sali and 


\section{Disharmonic orders}

(c) Initial-over-final

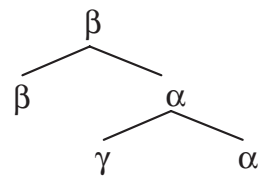

(d) Final-over-initial

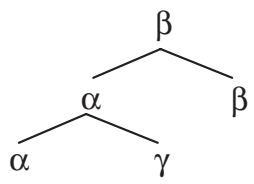

Latterly attention has turned to a subset of these disharmonic orders, which, more than being simply cross-linguistically dispreferred, appear not to surface at all (Holmberg 2000, Biberauer et al. 2007 and subsequent work). Research in this area is concerned with two questions: Firstly, which are the disharmonic orders that do not exist? Secondly, why are such orders absent?

This paper attempts to answer both questions by motivating the following generalisations:

(2) (a) Where $\alpha$ belongs to a certain class of functional heads (which we will term 'linkers'), the disharmonic orders in (Ic, d) are ungrammatical as base-generated structures.

(b) Where $\alpha$ is any other head, the disharmonic orders in (Ic, d) are simply cross-linguistically dispreferred as base-generated structures (as long as any requirement over linkers can otherwise be satisfied).

It will be shown that the difference between the two classes, and hence the difference in the two generalisations, is determined by semantics.

An alternative generalisation over absent disharmonic orders is provided by the Final-Over-Final Constraint (henceforth FOFC, Holmberg 2000, Biberauer et al. 2007 and subsequent work):

\section{(3) The Final-Over-Final Constraint (FOFC)}

If $\alpha$ is a head-initial phrase and $\beta$ is a phrase immediately dominating $\alpha$, then $\beta$ must be head-initial. If $\alpha$ is a head-final phrase, and $\beta$ is a phrase immediately dominating $\alpha$, then $\beta$ can be head-initial or head-final, where:

(i) $\alpha$ and $\beta$ are in the same extended projection [categorially nondistinct, and $\alpha \mathrm{P}$ is a complement to $\beta$ ]

(ii) $\alpha \mathrm{P}$ has not been $\mathrm{A}^{\prime}$-moved to $\operatorname{Spec} \beta \mathrm{P}^{2}$

(Biberauer, Holmberg \& Roberts 20I0: 53, ex. ( $\left.\mathrm{I}^{\prime \prime \prime}\right)$ )

Hamza Tidjani for Lagwan data and judgments, and to Ali Mirshahi for Persian judgments. This research is supported by the AHRC. Any errors are of course my own.

[2] Note that Biberauer et al.'s (20I0) definition of extended projection differs from Grimshaw's (I99I, 2005), a matter we return to in Section 5.I. 
FOFC makes a very different prediction to the generalisations in (2). This prediction can be paraphrased as follows (leaving aside the question of $\mathrm{A}^{\prime}$-movement):

(4) Wherever $\alpha \mathrm{P}$ is a categorially non-distinct complement of $\beta$, the finalover-initial order in (Id) is ungrammatical.

If, as I shall propose here, the generalisations in (2) are correct, FOFC fails empirically as a universal by being both too weak and too strong (see Hawkins 20I0): too weak, because it fails to predict the ungrammaticality of (Ic) (initial-over-final order) where $\alpha$ is a linker (see (2a)); too strong, because it incorrectly predicts the ungrammaticality of (Id) (final-over-initial order) where $\alpha$ is any other head, $\alpha \mathrm{P}$ being a categorially non-distinct complement of $\beta$ (see (2b)).

This paper will propose that there are two types of ordering constraints present in natural language, and that the generalisations in (2) obtain as a result of their interactions. Firstly, there are general ordering constraints relating to harmony - these are universal, and always interact in the same way. Secondly, there are constraints referring to specific syntactic features: either lexical features or features encoding semantics. Constraints of this kind require heads bearing specific syntactic features to appear either initially or finally in their (partial) projection, which may result in disharmony. The set of constraints of this latter kind that is active within a given language is subject to cross-linguistic variation. It is possible for these specific constraints to override the general rules of harmony; however, we will see that, given any possible interaction between the two, the generalisation in (2a) will always hold.

Crucially, I will propose that there is a class of functional heads - LINKERS - which are entirely lacking in syntactic features encoding semantics; that is, they do not add to the compositional semantics of their extended projection, but serve only as a syntactic and phonological means of marking a relationship. Given their status as semantically vacuous functional heads, there is only one kind of word order constraint that is applicable-the universal constraints determining harmonic word order. Constraints referring to either lexical heads or syntactic features encoding semantics cannot apply, since there are no such features available in linkers. It is this contrast between the type of constraint that can apply to linkers and the wider set of constraints that can apply to any other head that leads to the generalisations in (2).

Before looking at the constraints themselves, we begin with a brief introduction to linkers. A linker is a syntactically independent, semantically vacuous word serving only to mark the presence of an independently existing relationship-modification or $\theta$-role assignment - between a head in one extended projection and a distinct dependent extended projection, 
the dependent being sister to (a projection of) the head. ${ }^{3}$ As such, the linker makes no contribution to the compositional semantics of its extended projection and so only appears where the relevant relationship exists. Examples of linkers include subordinating complementisers, such as that in English, specialised relative clause markers, or relativisers, such as $c o$ in Czech ((5) below), purely functional, as opposed to lexical, adpositions, such as of in English, and general linkers or markers of subordination in the complex noun phrase, such as the ezafe/izafe(t) in Indo-Iranian and de in Mandarin Chinese ((6)-(7) below; see also Rubin 2002, Den Dikken \& Singhapreecha 2004, Philip 20I2)., ${ }^{4,5}$ All of these occur only in the context of marking a head-dependent relationship. For example, subordinating complementisers and relative clause markers do not appear in matrix clauses; the linkers in (6)-(7) do not occur where the adjective or PP is predicative.

(5) dopisu [co Vám poslali] Czech

letter LNK you.PL.DAT sent

'the letter that they sent you' ${ }^{6}$

(Fried 20I0: 20, ex. (5a))

(6) $[$ hao de $]$ shu

Mandarin Chinese

good LNK book

'good books'

(Den Dikken \& Singhapreecha 2004: 34, ex. (46))

(7) [guanyu Chomsky de] shu about Chomsky LNK book

'book about Chomsky'

Mandarin Chinese

(Paul 2007: 9, ex. (22a))

Similarly, the linker does not initiate the relationship between head and dependent; it simply marks its presence. For example, consider a head such

[3] Throughout, I use the term extended projection in the conventional sense, as first defined by Grimshaw (I99I, 2005), as opposed to Biberauer et al.'s (2010) redefinition.

[4] Relative operators will not be included, since these make a semantic contribution.

[5] In some languages, such as Tagalog (Malayo-Polynesian), a single morpheme (na/-ng in Tagalog) is used as subordinating complementiser, relative clause marker and linker in the complex noun phrase, confirming that they form a natural class.

[6] Abbreviations:=clitic; ' high tone; ' mid tone (Ma'di), long vowel (Akkadian, Batad Ifugao, Evenki, Pashto, Persian); ' low tone; nasalised (Bai, Canela-Krahô), palatal (Malayalam); I, 2, 3 first, second, third person $;{ }^{21},{ }^{33},{ }^{42}$, etc. tone markings; ACC accusative; CL classifier; COMPL completive; DAT dative; DET determiner; ERG ergative; EXP experiential; F feminine; FUT future; GEN genitive; IMMED immediate; IMP imperative; IMPF imperfective; LNK linker; LOC locative; M masculine; MANNER manner; NCI negative concord item; NEG negative; NOM nominative; NONPST non-past; OBJ object; PART participle; PERF perfective; PL plural; PROG progressive; PST past; Q interrogative; REFL reflexive; REL relative; sG singular; STAT stative; T tense; TOP topic; VENT ventive 
as the verb know. This assigns a $\theta$-role to its complement, which may be either clausal or nominal in category, as shown in (8).
(a) I know [(that) it's Rupert].
English
(b) I know [(*that) your middle name].

In the former case, (8a), the finite clausal complement is optionally marked by the overt linker that. Although in (8b) the relationship between the verb and its complement - this time nominal - is identical in terms of $\theta$-assignment, here there is no linker. The fact that the relationship remains the same whether or not there is a linker indicates that the linker has no role in initiating the relationship; it is simply used to mark the presence of the relationship where the complement is both clausal and finite. ${ }^{7}$ More generally, the statement that linkers do not initiate the relationship they mark is confirmed by the fact that the subordination relationships marked by linkers such as subordinating complementisers, relativisers and linkers in the noun phrase occur with no marking at all in many languages. (Compare for example (6)-(7) with their English translations.)

It is important to note that this definition of linkers, while it encompasses purely subordinating complementisers, excludes semantically contentful adverbial conjunctions such as because. Although because, like that, only appears in the presence of a relationship, unlike that, it does not mark an independently existing relationship, but INITIATES the relationship; a causal relationship cannot occur in the relevant structure without it.

The remainder of this paper is organised as follows. Section 2 introduces the notion of harmony as a universal phenomenon. Section 3 shows how disharmony may come about for certain heads, due to the language-specific ranking of constraints referring to specific syntactic features. Section 4 presents the results where harmony and disharmony interact. Section 5 compares the findings with the predictions of FOFC.

\section{THE UNIVERSAL NOTION OF HARMONY}

We begin by considering the notion of harmonic word order. In the literature, a number of cross-linguistic word order tendencies have been observed. In this section I formulate these tendencies in terms of violable constraints, and propose that the notion of harmony in grammar is defined by the interaction of these independently motivated, violable, constraints in a

[7] Note that while in this case finiteness is marked on the linker, it is not the linker itself, but rather the lower head $\mathrm{T}$, that introduces the finite feature; the linker does not introduce any semantics. Similarly, it may be that the head if, which appears in complementary distribution with that, does not introduce, but simply marks, the presence of a wh-feature introduced lower in the clause. (Note that in many languages subordination and interrogation are expressed by separate heads; see for example Biberauer et al. 20I0: 34-35 and example (50) below.) 
universal ranking. In addition, I argue that these word order constraints apply only to base-generated structures, these base-generated structures showing a greater diversity, and movement being more restricted, than under certain views of syntax. Empirical evidence for the proposed ranking of constraints, and its application to the base-generated structure only, will then be provided by a study of the restrictions placed on the cross-linguistic distribution of subordinating complementisers.

Before considering the relevant constraints, we begin with the more general question of what level of syntactic representation is relevant to the notion of harmony. This is a matter that depends largely on the view adopted of the mapping of syntactic structure to linear order. One such view is expressed by Kayne's (1994) Linear Correspondence Axiom, which assumes that there is a single base-generated order, and any variant of this order results from movement. As shown by Abels \& Neeleman (2009, 20I2), however, a restrictive theory of movement cannot be maintained under this hypothesis if we are to account for the full range of data. Moreover, in many cases movement must be assumed purely on the basis of the surface word order, without any independent evidence. Instead, Abels \& Neeleman adopt the more traditional view, whereby there are no universal ordering - merely hierarchical - restrictions on base-generation. This approach has the advantage of being able to maintain a more restrictive theory of movement. Under this view, movement is much rarer, and need only be assumed where there is independent evidence. Given that the unmarked order is determined to a much larger extent by the base-generated structure, it is not unreasonable to assume that word order constraints refer to this same base-generated order. $^{8}$

The violable word order constraints concerned with harmony are formulated below:

(9) Head-Proximate Filter

The highest head in a complete extended projection must be contiguous with the lexical head of its superordinate extended projection.

(Io) Final-Clause Constraint

A clausal dependent must follow the lexical head of its superordinate extended projection.

(II) Head Uniformity Constraint

A functional head must match the lexical head of its extended projection in the direction of headedness.

[8] The claim that word order constraints do not apply to orders resulting from obvious movement is by no means unprecedented. FOFC does not apply to structures resulting from A'-movement (see (3) above); while Williams' (I982) Head-Final Filter applies only to base-generated structures. 
The Head-Proximate Filter has its correlates in Generative Grammar in the Head-Final Filter (Williams 1982), in Functional Grammar in Rijkhoff's (1984, I986, 2002) Principle of Head Proximity, and in the principle of Early Immediate Constituents in Hawkins' (1990, 1994) performance theory of grammar. (See fn. 9 below for a discussion of the differences between these constraints and the Head-Proximate Filter.) The Head-Proximate Filter specifies a requirement for the lexical head of one extended projection and the highest head in the extended projection of its dependent to be linearly as close to each other as possible. For example, Rijkhoff (2002: 26I-263) points out that the data from Hawkins' (1983: 28I-290) expanded sample shows a general tendency for languages to avoid placing adjectives and possessor NPs between the noun they modify and its selecting verb; in more concrete terms, there is a tendency for a noun to precede its dependents in VO languages and to follow its dependents in OV languages, such that the noun is as close as possible to its selecting head, the verb (see Greenberg I963: 85-90; also (33) below). A similar concept is found in the Head-Final Filter, where, in the Germanic and Romance languages in which it applies (see Escribano 2004: I, fn. 2 for references), prenominal modification is only possible where the modifier is head-final, and therefore its head is immediately adjacent to the noun phrase it modifies. Escribano (2004: 2-3) shows that the effects of the Head-Final Filter in the languages in which it operates extend beyond the nominal domain to other categories. Most importantly, there is evidence that the Head-Final Filter operates exclusively over basegenerated structures; structures that conform on the surface, but contain a trace to the right of the head of the modifier, such that the prenominal modifier is head-initial (as in verbal passives), are ungrammatical (Williams I982), while structures that contain a surface violation as a result of leftwards movement of the head-initial modifier from posthead to prehead position are grammatical (Escribano 2004: 4). The Head-Proximate Filter that I am proposing here simply extends the Head-Final Filter to include its mirror image. Like the Head-Final Filter, it is concerned with the base-generated structure. ${ }^{9}$

The second constraint, the Final-Clause requirement, is derived from Dryer's (1980) Sentential NP Position Hierarchy. Looking at the

[9] Here the Head-Proximate Filter differs (as far as I can see) from both Rijkhoff's Principle of Head Proximity and Hawkins' concept of Early Immediate Constituents. The latter relates purely to ease of processing; therefore it is presumably concerned only with surface word order. Similarly, there is a further fundamental difference between the Head-Proximate Filter and Rijkhoff's Principle of Head Proximity. This principle expresses a preference for LEXICAL head of the dependent to be linearly contiguous with the head of its superordinate domain. The Head-Proximate Filter requires the HIGHEST head in the extended projection of the dependent, which may or may not be the lexical head, to be linearly contiguous with the superordinate lexical head. We will see in the remainder of this paper that the restriction to base-generated structures and to the highest head of the dependent captures a wider range of data. 
cross-linguistic distribution of clausal arguments, Dryer established the hierarchy in (I2).

\section{(I2) Sentential NP Position Hierarchy}

clause-final position $>$ clause-initial position $>$ clause-internal position

(Dryer 1980: I26)

This hierarchy states that if a language allows any argument to appear in a given position on the hierarchy, it will allow clausal arguments in that position; a position further to the left, where available, will be preferred over any position to its right. This is confirmed by the fact that clausal complements of verbs are allowed in final position in both VO and OV languages, but preverbal complement clauses are not found in VO languages, which by definition always allow arguments in final position (Dryer 1980; Hawkins I994: Section 5.6.I; see also the typology in (I4) below). Of relevance to us here is the fact that the clause-final position is preferred over any other: from this we derive the Final-Clause requirement as a violable constraint, formulated in (Io) above.

The first two constraints we have looked at have been concerned with ordering between the lexical head of a superordinate extended projection and a dependent, or subordinate, extended projection. We move now to the final constraint, Head Uniformity, which is concerned with the order within the extended projection itself. This constraint is perhaps the best known among harmonic word order constraints. There is a preference for heads in a given language or domain to be consistent in directionality of headedness: either uniformly head-initial or head-final (see Natural Serialisation Principle, Bartsch \& Vennemann 1972: I36; Head Parameter, inter alia Chomsky I98I; Branching Direction Theory, Dryer 1992, 2009a).

We will see that the three relevant constraints - the Head-Proximate Filter, Final-Clause, and Head Uniformity-are not always mutually compatible. Where the three compete it is invariably the Head-Proximate Filter that takes precedence; the constraints are hierarchically ordered $a$ la Optimality Theory in the following, universal, ranking:

\section{(I3) Harmonic Word Order Ranking}

\section{Head-Proximate Filter > > Final-Clause, Head Uniformity}

It is worthwhile at this point saying a word on the proposed universality of the Harmonic Word Order Ranking. While Optimality Theory generally allows for constraints to be ranked differently in different languages, language-independent, fixed rankings are also found where there are pressures from some grammar-external system-Chomsky's (2005) third factor(e.g. the sonority hierarchy). In this case research has shown that constraints of the type that make up the Harmonic Word Order Ranking are motivated by ease and efficiency of processing (Hawkins 1990 and subsequent work). Given that principles of processing do not vary from language to language, 
it is to be expected that the ranking of these constraints should remain uniform across languages.

The application of this ranking can be seen most clearly in the crosslinguistic distribution of subordinating complementisers (henceforth simply 'complementiser') heading clausal complements of verbs. ${ }^{10}$ Typological studies have shown that the data is characterised by two striking left-right asymmetries: firstly, only initial complementisers are found in VO languages, while OV languages allow both initial and final complementisers; secondly, only postverbal complement clauses are attested in VO languages, whereas in OV languages, both preverbal and postverbal complement clauses are permitted. In addition, the complementiser must be base-generated such that it intervenes linearly between its selecting verb and the complement clause. ${ }^{11}$ This leads to a single grammatical order for VO languages, and two possible orders for OV languages (statistics from Dryer 2009a: 199-200; see also Hawkins 1990 and subsequent work; Dryer I992: I02; Bayer 1996 and subsequent work): ${ }^{12}$

(I4) VO languages

V[CVO] I40 languages $\quad(\mathrm{I} 00 \%$ of VO)
$*[\mathrm{VOC}] \mathrm{V}$ o languages
$* \mathrm{~V}[\mathrm{VOC}]$ o languages
$*[\mathrm{CVO}] \mathrm{V}$ o languages

$\begin{array}{ll}\text { OV languages } & \\ \text { V[COV] 21 languages } & (45 \% \text { of OV }) \\ \text { [OVC]V 26 languages } & (55 \% \text { of OV }) \\ \text { *V[OVC] o languages } & \\ *[\mathrm{COV}] \mathrm{V} \text { o languages } & \end{array}$

The tableaux below show that this typological pattern is precisely captured by the Harmonic Word Order Ranking. In VO languages, shown in (I5), it is possible to obey all three constraints, resulting in a single optimal order - the consistently head-initial order represented by candidate (I5a).

[Io] There is a particular reason for this, which we will see later on (Section 4): because we are dealing here with a head and dependent of the same category, there is no interference from the second kind of word order constraint (which we will look at in Section 3), which can lead to disharmony.

[II] The fact that complementisers like that do not intervene between their complement and the matrix verb when they head a clausal subject (e.g. That John was lazy was common knowl$e d g e$ ) is unproblematic: the clausal 'subject' is generally considered to be a topic associated with a null pronoun - the true subject (Koster I978, Alrenga 2005).

[I2] I have removed from Dryer's data the languages Khoekhoe and Harar Oromo since these are not true instances of C-headed complements of verbs. See fn. I8. 


\begin{tabular}{|l||c|c|c|}
\hline \multicolumn{1}{|c|}{ VO language } & HEAD-PROXIMATE & FINAL-ClaUSE & HEAD UNIFORMITY \\
\hline a. $\mathrm{V}[\mathrm{CVO}]$ & & & \\
\hline b. $[\mathrm{VOC}] \mathrm{V}$ & & $* !$ & $* !$ \\
\hline c. $\quad \mathrm{V}[\mathrm{VOC}]$ & $* !$ & & $*$ \\
\hline d. $\quad[\mathrm{CVO}] \mathrm{V}$ & $* !$ & $*$ & \\
\hline
\end{tabular}

The dominant constraint, the Head-Proximate Filter, requires the highest head in the extended projection of the dependent-that is the complementiser - to be linearly contiguous with its superordinate lexical head - the selecting verb. Candidates (I5a, b) both obey this constraint. This constraint applies only to the complementiser here, not to either verb, because the Head-Proximate Filter only applies where we are dealing with heads in separate extended projections, and then only to the highest head in the complete extended projection of the dependent. Of the candidates that obey the Head-Proximate Filter, (I5a) is chosen over (I5b), because (I5a) also obeys Final-Clause and Head Uniformity, both of which are violated by (I5b): the dependent clause in (I5a) follows its superordinate lexical head, the matrix verb, and the complementiser matches the lexical head of its extended projection - the lower verb - in direction of headedness, both being headinitial.

On the other hand, in OV languages, shown in (I6), there is no single order that obeys all three constraints.

\begin{tabular}{|l||c|c:c|}
\hline OV language & HEAD-PROXIMATE & FINAL-ClaUSE & HEAD UNIFORMITY \\
\hline a. $\mathrm{V}[\mathrm{COV}]$ & & & $*$ \\
\hline b. $[\mathrm{OVC}] \mathrm{V}$ & & $*$ & \\
\hline c. $\quad \mathrm{V}[\mathrm{OVC}]$ & $* !$ & & $*$ \\
\hline d. $\quad[\mathrm{COV}] \mathrm{V}$ & $* !$ & $*$ & \\
\hline
\end{tabular}

Therefore, in order to obey the dominant constraint, the Head-Proximate Filter, either Final-Clause or Head Uniformity must be violated, resulting in two possible orders: the consistently head-final order (I6b) and the supposedly 'disharmonic' initial-over-final order (I6a). Furthermore, notice that if, as I argue here, harmony is defined by the ranking in (I3), we have an explanation for why the supposedly 'harmonic' $[[\mathrm{OV}] \mathrm{C}]$ and 'disharmonic' $[\mathrm{C}[\mathrm{OV}]]$ are more-or-less equally common among OV languages (see (I4)); according to the ranking in (I3), both are equally harmonic.

We have seen then that, at least as regards subordinating complementisers, the Harmonic Word Order Ranking correctly derives both the grammatical and the ungrammatical orders. However, there is a second claim to be considered here: if it is true that the Harmonic Word Order Ranking is concerned with base-generated structures, it is predicted not only that the orders $[\mathrm{V}[\mathrm{CVO}]],[\mathrm{V}[\mathrm{COV}]]$ and $[[\mathrm{OVC}] \mathrm{V}]$ should be attested, but that these orders should occur as base-generated structures. 
That the order [V[CVO]] is base-generated I take as uncontroversial. This leaves the two orders attested in OV languages: [[OVC]V] and [V[COV]]. Given that the complement clause can appear on either side of the verb, one might suppose that one order is derived from the other through movement. However, data from a number of languages suggests that this is not the case. In both cases, the complement clause, whether pre- or postverbal, is not an island for extraction. The validity of this criterion is confirmed by data following later, where extraction is impossible from a complement clause which has undergone movement (see (23)-(24) below). The lack of island effects for the orders $[[\mathrm{OVC}] \mathrm{V}]$ and $[\mathrm{V}[\mathrm{COV}]]$ is demonstrated below by examples from the Southern Dravidian language Malayalam, displaying the order [[OVC]V], and Persian (or Farsi), which has [V[COV]]. (Note that the complementiser, as a linker, is simply glossed LNK.)

(I7) [aa kuLatt-il $]_{\mathrm{i}}$ ayaaL [waliya miinu-kaL $t_{\mathrm{i}}$ uNTə that pond-Loc he big fish-PL have ennə] paraññu.

Malayalam

LNK said

'In that pond, he said that there are big fish.'

(Bayer 1999: 256, ex. (35), citing p.c. from Hany Babu)

(I8) [Un ketāb-ā $=$ ro $_{\mathrm{i}}$ man mi-dun-am [ke Kimiyā $t_{\mathrm{i}}$ that book-PL $=$ ACC I IMPF-know-ISG LNK Kimea xar-id-e].

Persian

buy-PERF-3SG

'As for those books, I know that Kimea has bought (them).'

(Karimi 200I: 84, ex. (69))

In the Malayalam example (I7) an adjunct PP, and in the Persian example (I8) the direct object, is extracted from the complement clause to sentenceinitial position. Analogous evidence from Japanese, Afrikaans, Dutch, German, Hindi-Urdu, and Turkish can be found in Bayer (I999: 256), Karimi (200I), Biberauer, Newton \& Sheehan (2009), Biberauer \& Sheehan (2010: Section 4.2) and references cited in these works.

The fact that the complement clause may be base-generated on either side of the verb in OV languages - as long as the complementiser is adjacent to the verb - is particularly striking in certain OV languages that allow both head-initial and head-final complementisers. This phenomenon is found mainly in Indo-Aryan languages with close geographical or historical contact with Dravidian, such as Assamese, Bengali (or Bangla), Oriya and Marathi, and also the Turkic language Uzbek and the Volta-Congo language Vata (or Dida) (Bayer 1996 and subsequent work; Cinque 2005: 55). In such languages, as predicted by the Harmonic Word Order Ranking and the consequent tableau in (I6) above, all complementiser-initial clauses 
are obligatorily postverbal, while complementiser-final clauses are uniformly preverbal. This is demonstrated in (I9) and (20) by Bengali, which has two optional complementisers: bole, which is clause-final, and je, which is clause-initial. The complementiser bole is only possible where the embedded clause is preverbal, while je only appears where the embedded clause is postverbal:

(I9) (a) chele-ta [or baba aS-be (bole)] Sune-che.

Bengali boy-CL his father come-FUT.3 LNK hear-PERF.3

(b) chele-ta Sune-che [or baba aS-be (*?bole)]. boy-CL hear-PERF.3 his father come-FUT.3 LNK 'The boy has heard that his father will come.'

(Bayer 1996: 255, ex. (9))

(20) (a) chele-ta $[(* \mathbf{j} \mathbf{j})$ or baba aS-be $]$ Sune-che. Bengali boy-CL LNK his father come-FUT.3 hear-PERF.3

(b) chele-ta Sune-che [(je) or baba aS-be]. boy-CL hear-PERF.3 LNK his father come-FUT.3 'The boy has heard that his father will come.'

(Bayer 1996: 255, ex. (II))

Again, there is evidence that both the preverbal clause, headed by bole, and the postverbal clause, headed by je, are base-generated; neither is an island for extraction:

(2I) [bas theke $]_{\mathrm{i}}$ amar didi [Otogulo duronto bacca $t_{\mathrm{i}}$ bus from my sister so.many uncontrollable children laphi-ye nam-be bole] bhabe ni. Bengali jump-PSTPART descend-FUT. 3 LNK think.3 NEG.PST

'From the bus, my sister didn't think that so many uncontrollable children would jump off.'

(Bayer 1999: 255-256, ex. (34b))

(22) kriSno mEleria-te ${ }_{\mathrm{i}}$ bhab-che [je $\operatorname{ram} t_{\mathrm{i}}$ mara

Krishna malaria-LOC think-PERF.3 LNK Ram die

gE-che].

Bengali go-PERF.3

'Krishna thinks that Ram died of malaria.'

(Simpson \& Bhattacharya 2003: I30, ex. (8))

We have seen then that not only does the Harmonic Word Order Ranking successfully capture the attested cross-linguistic distribution of complementisers, but also the prediction that the three optimal candidates in (I5) and (I6) should be base-generated as such is borne out. One final consequence remains to be explored: while the unsuccessful candidates are predicted not to occur as base-generated structures, the possibility is left open that they may occur as surface structures following movement. If we do 
therefore come across any of the orders found among the unsuccessful candidates, we expect to find evidence of movement.

Certain rigid OV languages, such as Japanese and Malayalam, allow the surface order V[OVC] as a marked variant of the consistently head-final order [[OVC]V]. ${ }^{13}$ This is exemplified in (23a) for Malayalam and (24a) for Japanese, the postverbal clause being deaccented. Since this order is ruled out as a base-generated structure by the Harmonic Word Order Ranking (see (I6)), it is predicted that the complementiser-final postverbal clause in (23)-(24) has moved from preverbal position, and will consequently be an island for extraction. The (b) examples show that this prediction is borne out.

(23) (a) ayaaL paraññu [waliya miinu-kaL aa kuLatt-il he said big fish-PL that pond-LOC uNTə ennə].

Malayalam have LNK

'He said that there are big fish in that pond.'

(b) *[aa kuLatt-il $]_{\mathrm{i}}$ ayaaL paraññu [waliya miinu-kaL $t_{\mathrm{i}}$ uNTə ennə] that pond-LOC he said big fish-PL have LNK

(24) (a) $\%$ Mary $=$ wa it $=$ ta,$\quad[\mathrm{John}=$ ga $\quad$ zibunzisin $=0$ aisiteiru Mary $=$ TOP say $=$ PST John $=$ NOM self $=$ ACC $\quad$ love to].

Japanese

LNK

'Mary said that John loves himself.'

(b) $*[\text { Zibunzisin }=\text { o }]_{\mathrm{i}}$ Mary $=$ wa it $=$ ta,$\quad\left[\mathrm{John}=\right.$ ga $t_{\mathrm{i}}$ aisiteiru to $]$. self $=$ ACC $\quad$ Mary $=$ TOP say $=$ PST John $=$ NOM love $\quad$ LNK

This clearly contrasts firstly with the parallel Malayalam example in (I7) and the Bengali example in (2I), and secondly with the Persian and Bengali examples in (I8) and (22), where extraction from either a complementiserfinal clause in PREVERBAL position or from a postverbal complement clause with an INITIAL complementiser poses no problem - both these structures being permitted by the Harmonic Word Order Ranking and the consequent tableau in (I6).

I have argued here that the ordering properties of complementisers are determined by the Harmonic Word Order Ranking in (I3) and the resulting tableaux in (I5)-(I6). This is not to say however that a complementiser as a lexical item can never have its own ordering statement. Indeed, we have

[13] Other languages allowing this order as a marked variant of [[OVC]V] include Telugu (also Southern Dravidian) and the Ge-Kaingang language Canela-Krahô (see Krishnamurti \& Gwynn 1985; Popjes \& Popjes I986; Cinque 2005). While I have no information on the extraction possibilities for these languages, given the marked nature of the postverbal variant, it seems highly likely that, like Malayalam and Japanese, the complement is always base-generated in preverbal position. 
already seen evidence to the contrary for Bengali (as well as the other OV languages with a hybrid complementiser system). Examples (19)-(20) above show that in Bengali the complementiser je can only appear in initial position, selecting a complement to its right, while bole must be final, selecting a complement to its left. ${ }^{14}$ What is important is that any specialisation within the lexicon must remain within the confines of the principles of the grammar. The Harmonic Word Order Ranking defines what is a possible grammar in terms of the position of complementisers. An individual complementiser may therefore have its own ordering statement, as long as the result is congruous with the Harmonic Word Order Ranking. Therefore, by (I6), it is possible for a complementiser in an OV language to have either an initial or a final ordering statement. On the other hand, (I5) shows us that a complementiser with a final ordering statement will not be allowed in a VO language.

Finally, note that the complementiser data we have studied in this section serves as an initial piece of evidence supporting the generalisation in (2a): as a type of linker, complementisers should be base-generated such that they intervene linearly between their complement and the head (the higher verb) that selects them. The typology in (I4) provides the empirical evidence, while the tableaux in (I5) and (I6) demonstrate that this result is predicted by the universal Harmonic Word Order Ranking in (13).

\section{DISHARMONY}

In the previous section, I suggested that the notion of harmonic word order is determined by the ranking of independently motivated harmonic word order constraints in a universal Harmonic Word Order Ranking in (13). In this section I propose that there is a second type of word order constraint made available by the grammar, which is not concerned with harmony. Constraints of this kind refer to specific syntactic features of a head, and require them to appear either initially or finally within any level of the projection of this head. There are two types of features that can be mentioned by these ordering constraints: the categorial features of a lexical head and features encoding semantics. In principle these ordering constraints can therefore refer to any head as long as it is either lexical or has syntactic features encoding semantics. There is however no expectation that the same lexical or semantic features should appear in the same position cross-linguistically. The

[I4] Note that je and bole are not simply different phonological realisations of the same linker. The choice of complementiser is partly determined by both syntactic and semantic environment: $j e$ is used to mark any finite clause, whether complement of a verb, or a relative clause; bole is used for both finite and non-finite clauses, but can only be used where its selecting verb is associated with some kind of speech act (Bayer 200I and references cited there). Note that the properties of finiteness and of the semantics of speech are not introduced by the linker itself, but by the heads $\mathrm{T}$ and $\mathrm{V}$ respectively. The semantically vacuous linker simply marks these properties. 
ranking of constraints referring to specific syntactic features therefore freely varies from language to language both with respect to the constraints of the Harmonic Word Order Ranking (provided it maintains its own internal ranking) and with respect to other constraints of the same kind. Where these constraints conflict with, and override, any constraints of the Harmonic Word Order Ranking, disharmony arises. Since different languages each have their own ranking, we expect cross-linguistic diversity in terms of the extent of disharmony within individual languages.

We take the syntactic feature of negation by way of illustration, though what follows should apply to any lexical head or to any functional head with syntactic features referring to semantics. For example, disharmony is relatively common for negative markers. As operators, negative markers certainly have syntactic features referring to semantics. Therefore it is possible for ordering rules of the type described above to refer to the negative semantics of the negation head within a given language and require it to appear in a given position. ${ }^{15}$ The cross-linguistic situation confirms this. There is a tendency to place negative markers in one of two prominent positions (see Dryer 1988): initially within their projection, with the result that negation will be expressed as soon as possible, preventing a 'semantic garden path' (Jespersen 1917; Dryer I988: I02); or finally, the position reserved for new or significant information, often the locus of sentence stress (Mazzon 2004: 5). Now, if an OV language has a dominant ordering rule such that a head expressing negation must appear initially in its merger with the verb phrase, disharmony of the kind seen in (Ic) above will be found: the initial-over-final order [Neg[OV]]. In the same way, a VO language may have a dominant rule requiring the negative head to appear finally in its merger with its complement, resulting in the disharmonic order in (Id): the finalover-initial order [[VO]Neg].

The tableaux below illustrate this using Optimality Theory. Suppose that Universal Grammar makes available, in addition to the Harmonic Word Order Ranking, the competing sets of constraints Neg-Initial and Neg-Final. Constraints in the former set require the negation head to appear initially in its (partial) projection, the latter finally. There will be equivalent sets of initial and final constraints for every lexical head and for every head with syntactic features encoding semantics. Note that these are sets of constraints

[15] As pointed out by an anonymous referee, some languages (e.g. Formal French) have two negative markers yielding a single negation reading. This suggests that one of them does not contribute to the compositional semantics at LF. This situation is easily explained by Zeijlstra's (2004) theory of negation. The negative head enters the derivation with an uninterpretable [Neg] feature, which is deleted prior to LF by the interpretable [Neg] feature on the negative operator in its specifier. This means both markers have syntactic features referring to negative semantics, and hence it is possible for specific ordering rules to refer to these features. On the other hand, only the features of the negative operator in [Spec, NegP] will be available for interpretation at LF. 
applying to different levels or domains of projection. For example, there could be one Neg-Initial constraint applying to the domain of Neg and its complement and another applying to the maximal projection. In the case where we are dealing with a VO language, the disharmonic order [[VO]Neg] will arise whenever any Neg-Final constraint dominates both HeadUniformity and Neg-Initial. This is shown in the tableau in (25). The HeadProximate Filter does not apply here, since we are dealing with word order within a single extended projection (compare (9) above).

\begin{tabular}{|c|c|c|c|c|c|}
\hline VO language & $\begin{array}{c}\text { HEAD- } \\
\text { PROXIMATE }\end{array}$ & NEG-FINAL & $\begin{array}{l}\text { FINAL- } \\
\text { Clause }\end{array}$ & $\begin{array}{c}\text { HEAD } \\
\text { UNIFORMITY }\end{array}$ & NEG-INITIAL \\
\hline a. [VO]Neg & & & & $*$ & * \\
\hline b. $\quad \mathrm{Neg}[\mathrm{VO}]$ & & $* !$ & & & \\
\hline
\end{tabular}

However, for any ranking whereby Neg-Final is ranked lower than, or equally with, either one of Head Uniformity or Neg-Initial, the optimal output will be the harmonic order [Neg[VO]]. This is illustrated by the tableaux in (26)-(27).

\begin{tabular}{|l||c|c|c|c|c|}
\hline VO language & $\begin{array}{c}\text { HEAD- } \\
\text { PROXIMATE }\end{array}$ & $\begin{array}{c}\text { FinAL- } \\
\text { CLAUSE }\end{array}$ & $\begin{array}{c}\text { HEAD } \\
\text { UnIFORMITY }\end{array}$ & NEG-FinAL & NeG-INITIAL \\
\hline a. [VO]Neg & & & $*$ & & $* !$ \\
\hline b. Neg[VO] & & & & $*$ & \\
\hline
\end{tabular}

(27)

\begin{tabular}{|l||c|c|c|c|c|}
\hline VO language & $\begin{array}{c}\text { HEAD- } \\
\text { ProXIMATE }\end{array}$ & NEG-INITIAL & NEG-FINAL & $\begin{array}{c}\text { FINAL- } \\
\text { ClAuSE }\end{array}$ & $\begin{array}{c}\text { HEAD } \\
\text { UnIFORMITY }\end{array}$ \\
\hline a. $[\mathrm{VO}] \mathrm{Neg}$ & & $*$ & & & $* !$ \\
\hline b. Neg[VO] & & & $*$ & & \\
\hline
\end{tabular}

In (26), Neg-Final dominates Neg-Initial, but is ranked equally with Head Uniformity. The candidate displaying the harmonic order in (b). violates Neg-Final, but the disharmonic candidate in (a), which obeys this constraint, violates the equally ranked Head Uniformity, with the result that any violation of the lower ranked Neg-Initial becomes fatal. In (27), we see a similar situation, except that here it is Neg-Initial that is equally ranked with NegFinal, and the disharmonic candidate's violation of Head Uniformity that is fatal.

Of course, precisely the same results obtain where either Head Uniformity or Neg-Initial is ranked any higher, or Neg-Final is ranked any lower. In OV languages, we will expect the inverse results: the disharmonic order [Neg[OV]] will obtain only where Neg-Initial dominates both Head Uniformity and Neg-Final; for any other ranking, the harmonic order [[OV]Neg] will be optimal. We expect exactly the same results where Neg is replaced by any other head with syntactic features encoding semantics. 
Under this theory of constraints relating to specific syntactic features, the following predictions arise: firstly, disharmony is predicted to be possible cross-linguistically for any head, as long as this head is either lexical or has syntactic features encoding semantics (that is, for any head that is not a linker, see Section I above); secondly, for any given such head, disharmony is predicted to be comparatively infrequent, or cross-linguistically dispreferred. The conditions allowing disharmony to arise are such that there are more logically possible rankings resulting in harmony than those resulting in disharmony. ${ }^{16}$ (For example, of the thirteen logically possible rankings of the relevant constraints Head Uniformity, Neg-Initial and Neg-Final, seven invariably result in harmony as regards the order of the negative head in relation to the verb; three result in harmony for OV languages and disharmony for VO languages; three result in harmony for VO languages and disharmony for OV languages.) These predictions in fact lead to the generalisation in (2b). The findings of broad typological studies provide an initial indication that these predictions, and hence the generalisation in (2b), are borne out. This can be seen in the data in (28) and (29), concerning the extended projection of the verb.

(28) (a) Initial-over-initial [Aux[V O]] 79 languages (55\%)

(b) Final-over-final [[O V]Aux] 30 languages $(2 \mathrm{I} \%)$

(c) Initial-over-final $[\mathrm{Aux}[\mathrm{O} \mathrm{V}]]$ I9 languages ( $13 \%)$

(39\% of OV languages)

(d) Final-over-initial [[V O]Aux] I6 languages (II \%) ( $17 \%$ of VO languages)

(29) (a) Initial-over-initial [Q[V O]]

75 languages $(20 \%)$

(b) Final-over-final [[O V]Q] I27 languages $(34 \%)$

(c) Initial-over-final [Q[O V]] 34 languages $(9 \%)$

(2I\% of OV languages)

(d) Final-over-initial [[V O]Q] I35 languages $(36 \%)$

$(64 \% \text { of VO languages })^{17}$

Here the disharmonic orders in the (c) and (d) examples arise where some specific constraint of the type described above outranks Head Uniformity.

[16] This explains the tendency expected as far as the grammar alone is concerned. The empirical situation tells us there is indeed a general tendency towards harmony, but the extent of this varies considerably for different heads ((28)-(33)). Finer variation of this kind need not necessarily be explained by the grammar, but may result from functional considerations of the kind proposed by Hawkins (1994 and subsequent work).

[17] The high proportion of languages displaying the disharmonic order in (29d) is unexplained by the theory put forward here, at least as far as the grammar alone is concerned (but see fn. I6 above). There appears to be a general cross-linguistic preference for interrogation to be signalled at the end of a question, that is independent of the morphosyntax: even where interrogation is not marked by a specific morpheme, but by intonation, this distinctive intonation is reckoned from the end of the question (Greenberg 1963: 80, Universal 8). 
The data in (28), from Julien (2002: 330-356), shows the relative ordering of the verb and an auxiliary (independent tense, aspect or mood marker), and that in (29), from Bailey (2010: 29, Table I, using data from Dryer 2008a, b), that of the verb and a question particle.

Data from the nominal domain, where an NP containing a head noun modified by a possessive phrase is contained within a PP, from Hawkins (1994: 259, Table 5.2, using data from Hawkins 1983), shows the same, predicted, distribution:

(30) (a) Initial-over-initial [P[N PossP]] I34 languages (40\%)

(b) Final-over-final [[PossP N]P] I77 languages (53\%)

(c) Initial-over-final $[\mathrm{P}[$ PossP $\mathrm{N}]] \quad \mathrm{I} 4$ languages $(4 \%)$

( $7 \%$ of $\mathrm{N}$-final lgs)

(d) Final-over-initial [[N PossP]P] II languages (3\%)

( $8 \%$ of $\mathrm{N}$-initial lgs)

This kind of distribution is not limited to examples within a single extended projection. Precisely the same situation holds across extended projections (except where the relationship is marked by a linker). In this case the disharmonic orders arise due to some specific constraint referring to the semantic or lexical features of a head outranking the Head-Proximate Filter. This can be seen where the verb takes an adpositional complement, in (3I), using data from Dryer (2008c) and Sheehan (2008: Section 4, 20II: 47), and where it takes a nominal complement, in (32) and (33), showing data from Dryer (I992: I04, Table 34 and page 9I, Table 5):
(a) Initial-over-initial [V[P NP]]
(b) Final-over-final [[NP P]V]
(c) Initial-over-final
[V[NP P]]
(d) Final-over-initial
[[P NP]V]

4 I9 languages $(47 \%)$

427 languages $(48 \%)$

38 languages $(4 \%)$

( $8 \%$ of postpositional lgs)

I2 languages (I\%) ( $3 \%$ of prepositional lgs)

(32) (a) Initial-over-initial [V[D NP]]

37 genera $\quad(44 \%)$

(b) Final-over-final [[NP D]V]

I9 genera

$(23 \%)$

(c) Initial-over-final

[V[NP D]]

I5 genera

(I $8 \%)$

(29\% of VO genera)

(d) Final-over-initial

[[D NP]V]

I3 genera ( $15 \%)$

( $4 \mathrm{I} \%$ of $\mathrm{OV}$ genera)

(33) (a) Initial-over-initial [V[N PossP]] 63 genera (29\%)

(b) Final-over-final [[PossP N]V] I2 genera (52\%)

(c) Initial-over-final [V[PossP N]] 30 genera (I4\%)

(d) Final-over-initial [[N PossP]V] II2 genera (6\%) ( $16 \%$ of $\mathrm{N}$-initial genera) 
Consider now the situation with linkers. As discussed in Section I above, these are distinguished from other heads by their semantic vacuity. I have proposed here that disharmonic word orders arise as a result of ordering constraints within the grammar requiring a head with specified syntactic features encoding either lexicality or semantics to appear either initially or finally at some level of its projection. As we saw in the previous section, it is possible for a linker to have some kind of ordering statement as part of its lexical properties; however, this lexical ordering statement is strictly constrained by what is permitted in the grammar. What we do not expect to see applying to linkers are ordering constraints within the grammar of the type we have seen above, since these constraints refer exclusively to either lexical heads or features relating to semantics. The linker, however, by its very definition does not have such features. This explains why in the previous section, the position of subordinating complementisers (as a member of the class of linkers), and any possible lexical ordering statement, is always determined purely by the Harmonic Word Order Ranking in (13).

For example, we saw in the previous section that the complementisers $j e$ and bole in Bengali must obey the dominant constraint, the Head-Proximate Filter: complement clauses headed by initial je must be postverbal; those headed by final bole must be preverbal (see (19)-(20) above). Interestingly, it is possible for a clause headed by bole to appear postverbally - thereby violating the Head-Proximate Filter and hence the Harmonic Word Order Ranking - where it functions not as a subordinating complementiser, but heads a reason adverbial clause; in this case, bole does not mark the presence of an existing relationship (i.e. it is not a linker), but rather introduces its own relationship:

(34) ami ekhane eSe-chi [tomar SONge kOtha bol-bo

I here come-PST.I you with speech say-FUT.I bole].

Bengali

because

'I have come here in order to talk with you.'

(Bayer 1996: 255, ex. (I0))

This shows that there is no ban on postverbal bole-clauses per se, but simply those where the subordinating bole is semantically vacuous.

Similarly, a brief look at the diachronic development of the subordinating complementiser $k \bar{l}$ in the now extinct East Semitic language Akkadian provides direct support that it is indeed the lack of semantics in linkers that prohibits disharmonic word order. Akkadian was an SOV language spoken in ancient Mesopotamia. The subordinating complementiser $k \bar{\imath}$ developed over time from the adverbial conjunction kima. This morpheme kima occurred in initial position within the adverbial 
clause, which itself overwhelmingly appeared in preverbal position. An example containing kima from the Old Babylonian period is given in $(35)$ :

[kīma udammiqak-kunūši] dummikā-nim. Akkadian as ISG.do.favours.PST-to.you.PL do.favours.IMP.PL-to.me 'As I have done you favours, do me favours.'

(Deutscher 2007: 40, ex. (27))

Deutscher (2007: Section 4) documents a change in this morpheme's semantics of the kind comparative $>$ causal/purpose $>$ factive, leading to an eventual complete semantic bleaching; that is, a semantically contentful conjunction introducing an adverbial clause (kima) eventually became a subordinating complementiser heading a complement clause $(k \vec{\imath})$. Crucial to the theory put forward here, however - and its predictions - is the result of this change on word order. Throughout the diachronic change, the morpheme $k \bar{l}(m a)$ remains consistently clause-initial. However, the semantic bleaching of the morpheme is accompanied by a shift in position of the clause it heads: by the Middle Babylonian period complement clauses headed by the subordinating complementiser have shifted to postverbal position, while adverbial clauses remain preverbal:
(36) bēl-ī ìde [kī ultu èlâ dilipt-u lord-my 3SG.know LNK since ISG.arrive.PST trouble-NOM mahratan-ni]. 3FSG.contront.STAT-me
'My lord knows that since I arrived, trouble has befallen me.'

(Deutscher 2007: 5I, ex. (57))

In terms of the theory proposed in this paper, the shift of position for clauses headed by a subordinating complementiser, but not for those introduced by a semantically contentful adverbial conjunction, is easily understood. Where a clause is headed by a semantically vacuous subordinating complementiser, its position is determined uniquely by the Harmonic Word Order Ranking in (I3) (since no ordering constraint referring to either lexical features or semantics can apply). The tableau in (I6) shows us that the only grammatical option for an OV language with an initial subordinating complementiser involves a postverbal complement clause, giving the order attested in Akkadian, [V[COV]]. The finalover-initial order $[[\mathrm{COV}] \mathrm{V}]$ that would result if the subordinating complementiser retained the position of its semantically contentful predecessor would be disharmonic, and hence ungrammatical. On the other hand, examples such as (35) are unproblematic for the theory put forward here, since kima in this example is semantically contentful and 
therefore may have its own ordering constraints such that disharmony is possible. ${ }^{18}$

We have seen then both the theoretical motivation for part (b) of the generalisations in (2), and some empirical indications supporting the predictions: firstly statistical evidence from broad typological studies, and secondly by comparing semantically vacuous linkers with their semantically contentful synchronic or diachronic counterparts. The rest of this section will be devoted to studying some of the relevant disharmonic structures in greater detail.

We begin by considering markers of verbal properties such as tense, aspect and mood. Cross-linguistic studies such as Cinque (I999, 2009) and Julien (2002) firstly argue that these markers are functional heads in the extended verbal projection, and secondly show that these heads obey a strict, universal, hierarchy, or functional sequence (see also Grimshaw I99I, 2005 and references cited in the above works). These findings, which appear to be without exception, are based on the properties and placement of such markers both in head-initial and head-final languages.

Given, then, that markers of tense, aspect and mood - both initial and final - bear syntactic features encoding semantics, it is predicted that ordering constraints referring to these features should be able to target these heads, resulting in disharmony. We have already seen typological evidence, in (28) above, suggesting this prediction is borne out. Concrete examples given below in (37)-(39) support this evidence.

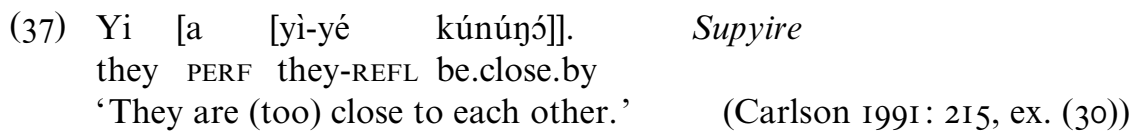

The example in (37) demonstrates the initial-over-final order in the North Volta-Congo language Supyire: the head-final VP is c-commanded by an initial aspect marker, $a$. (See also examples from the Ge-Kaingang language Canela-Krahô in (48) and (73) below, where a head-initial TP dominates a head-final VP.)

The inverse, final-over-initial, construction, whereby final tense or aspect markers are found in VO constructions, is also relatively common (Biberauer

[I8] A similar argument applies to the East Cushitic language Harar Oromo. Cinque (2005: 54, fn. I2), Dryer (2007: I00, 2009a: 200, ex. (27), p. 203, Table 4) and Biberauer \& Sheehan (20I0: 50 , fn. 24) point out that it appears to instantiate the disharmonic order *[[COV]V]. However, closer inspection reveals that the alleged 'complementiser', $a k k a$, is in fact a noun (see Owens 1985), and hence may be subject to its own ordering constraints. Cinque (2005) also claims that the languages D(h)ivehi (Insular Indo-Aryan), Lak(h)ota (Siouan) and Ngiti (Central Sudanic) instantiate the disharmonic order *[V[OVC]], as does Dryer (2009a: I4, ex. (27), p. I7, Table 4) for the Kwadi-Khoe language Khoekhoe. Like Harar Oromo, the alleged 'complementiser' here is in fact a noun (see Cain \& Gair 2000; Rood I973; Kutsch Lojenga I994: 395 and Güldemann 2006: 29, respectively). The disharmonic order therefore poses no problem. 
et al. 2007 and subsequent work; Dryer 2009b). This is shown in examples from the Central Sudanic language Bagirmi and the North Volta-Congo language Mumuye: the Bagirmi example in (38) shows a final aspect marker, ga, c-commanding a head-initial VP, while the final tense marker, $n i$, in the Mumuye example in (39) c-commands a head-initial AspP:

bis [sa ja tebire] ga. Bagirmi
dog eat meat yesterday COMPL
'The dog ate the meat yesterday.'

(Stevenson I969: 85, gloss Dryer 2009b: 344, ex. (I04))

(39) Znàsọ [dé baasé Ranti] ni.

Muтuуe

Znaso PERF mimic Ranti IMMED.FUT

'Znaso is about to mimic Ranti.'

(Dryer 2009b: 345, ex. (Io6b), citing Shimizu I983: II2)

The same results can be shown for the negation head, though the situation here is less straightforward. Firstly, negative particles are not always heads, but in many languages are adverbs. Secondly, where the negative marker is an adverb in a double negation language, NegP is usually not projected (Zeijlstra 2004). Moreover, where it is present, the position of NegP within the functional sequence varies from language to language (Laka I990; Ouhalla I99I; Zanuttini I99I, I997; Cinque I999; Julien 2002). It therefore does not necessarily follow that any attested sequence of either [Neg[OV]] or [[VO]Neg] exemplifies the predicted disharmonic structure; further investigation is required. Since NegP is generally not projected in double negation languages, we restrict our discussion to negative concord languages, which under most theories of negative concord must project NegP (inter alia Zanuttini I99I, Zeijlstra 2004). Our goal will therefore be to find negative concord languages in which the negative marker is a head, and this head differs in direction of headedness from the verb.

An example of the disharmonic initial-over-final order is found in the Northern Tungusic language Evenki, an OV language:
(a) Bi [dukuwūn-ma duku-cā-w].
I letter-OBJ write-PST-ISG
'I wrote a letter.'
(b) $\mathrm{Bi}[\partial-\mathrm{c} \overline{-}-\mathrm{w}$ [dukuwūn-ma duku-ra]].
I NEG-PST-ISG letter-OBJ write-PART
'I didn't write a letter.'
Evenki
(Payne I985: 2I3, ex. (3I))

This is demonstrated in example (4ob). It is clear here that the negative marker $\partial^{-}$is a head in the extended verbal projection, since it inflects for subject agreement and tense. Comparing the negative example in (4ob) with its affirmative counterpart in (40a), we see that these markings would 
otherwise appear on the lexical verb; in the negative example the lexical verb has a participial form. This confirms not only that the negative marker is a head, but also that the construction is monoclausal (see Payne I985: 2I2-2I4).

Turning now to the inverse disharmonic order, [[VO]Neg] is relatively common in central Africa (Dryer 2009b) and the Pacific region (Biberauer et al. 20I0: 56, citing Reesink 2002). Here again it can be shown that, at least in some cases, this final negative marker is a head, and thus instantiates the disharmonic final-over-initial order. Firstly, like Evenki, the Central Sudanic language Ma'di marks negation by means of a negative auxiliary. This is shown in (4I), where the final negation head is marked for tense, while the lexical verb remains unmarked. On the other hand, in the absence of negation, the same past/non-past distinction is marked on the lexical verb, as in (42).
(a) [m'-āwí djótī] kē.
$M a^{\prime} d i$ ISG-open door NEG.NONPST
'I won't open/am not opening the door/don't open doors.'

$$
\begin{aligned}
& \text { (b) [m'-āwí dótī] kūrù. } \\
& \text { ISG-open door NEG.PST } \\
& \text { 'I did not open the door.' }
\end{aligned}
$$

(Blackings \& Fabb 2003: I4, ex. (8))

(42) ká gbándà j̀ā.

(Blackings \& Fabb 2003: I4, ex. (7))

3SG cassava NONPST.eat

'He is eating/eats cassava.'

$M a{ }^{\prime} d i$

(Blackings \& Fabb 2003: I3, ex. (I))

In languages where the negative marker is an uninflected particle, there may still be evidence that this particle heads NegP. An example of such a language is Lagwan (or Logone, Central Chadic), which exhibits the order T[VO]Neg : ${ }^{19}$

(43) [Sà di-gìr kasku diyasin] sá.
FUT 3FSG-go market tomorrow NEG
'She won't go to the market tomorrow.'

A number of factors indicate that the negation marker here heads the projection NegP, and therefore exemplifies the disharmonic final-over-initial order. Firstly, example (44) provides evidence that Lagwan is a negative concord language, and therefore projects a NegP: the negative marker sá is required to license the negative concord item:

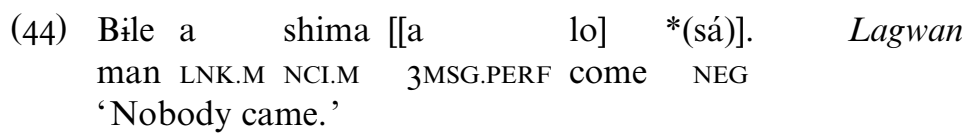

[19] Lagwan examples are taken from my fieldnotes, 2004-2005. 
Secondly, evidence from prohibitives shows that $\mathrm{NegP}$ has a fixed position in the Lagwan clause, dominating head-initial TP. Lagwan finite indicative clauses, as in (43) and (44), are marked for tense or aspect. Imperatives, on the other hand, lack any marking for tense or aspect, conforming to Kayne's (1992) conclusion that true imperatives are truncated structures lacking TP and any higher functional projections:

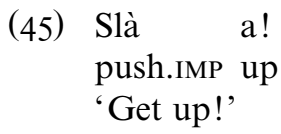

Lagwan

However, as is the case in many languages (see Zanuttini I99I and subsequent work, Kayne 1992, Zeijlstra 2004, among others), true negative imperatives are banned in Lagwan: as shown in (46a), it is not possible to attach the negative marker to an imperative clause. Instead, a surrogate is used, with the future tense head projected and marked for second person, as in $(46 b)$ :
(46)
(a) *Slà a sá!
push.IMP up NEG
(b) [Sà gi-sla a] sá!
FUT 2SG-push up NEG
'Don't get up!'
Lagwan

Zanuttini (1994, I996) argues that in languages banning true negative imperatives, NegP must dominate TP, thereby rendering a structure in which $\mathrm{NegP}$ is present but TP is absent (such as (46a)) ungrammatical. The fact that in Lagwan the ungrammatical structure is repaired by projecting TP seems to confirm this hypothesis.

Finally, there is evidence not only that NegP is projected, and that this $\mathrm{NegP}$ dominates head-initial TP and VP, but also that the final negative marker heads this projection, as opposed to being an adverb in its specifier. This evidence is found by applying the 'why not' test developed by Merchant (2006). The 'why not' construction is analysed as a form of phrasal adjunction, and hence only permitted where the negative marker is a maximal projection. In Lagwan, no such construction is possible:
(a) *[Age ghwani] sá? because what NEG
(b) *Sá [age ghwani]? NEG because what

Lagwan

We have seen then that heads marking tense, aspect and negation can all, as predicted, violate Head Uniformity, resulting in disharmony. The typological data in (29) above indicates that the same is true of interrogative 
heads. This is exemplified firstly in Canela-Krahô (Ge-Kaingang), an OV language with an initial interrogative marker, $x a \grave{~: ~}$
xà capi te [po curan]?
Canela-Krahô
Q Capi PST deer kill

'Did Capi kill a deer?'

(Popjes \& Popjes 1986: I57, ex. (I86))

The inverse disharmonic order, whereby a VO language has a final interrogative marker, is exhibited, among very many other languages, in Lagwan. Lagwan has a final interrogative head ( $d a)$, c-commanding an initial TP and VP. It occurs in both matrix and subordinate clauses, as shown in (49) and (50) respectively:

(49) [G-a mma ì gha] da? Lagwan
2SG-PERF leave her.ACC house Q
'Did you leave it at home?'

(50) Ndalu ngwa fine, ki [[bìle a shi a ISG.PROG look.at outside LNK man LNK.M some 3SG.M.PERF S-o gha] da].

enter-VENT house $\mathrm{Q}$

'I'm looking outside, (to see) whether someone has entered the house.' (Aaron Shryock, p.c.)

As regards interrogative markers and other discourse-related particles assumed to head projections in a layered CP, note that the semantic explanation for disharmony accounts for an otherwise anomalous situation. We have seen in the previous section that for subordinating complementisers, the disharmonic final-over-initial order is ungrammatical (see (I4)). However, this order is relatively common for other discourse-related heads assumed to belong to the $\mathrm{CP}$ domain, including, as we have seen, question particles (see Julien 2002: Section 3.6.I; Biberauer et al. 2007 and subsequent work; Paul to appear). If the presence or absence of disharmony is related to the presence or absence of syntactic features encoding semantics rather than directly to category, the anomaly disappears.

So far we have considered examples within a single extended projection - that is, examples where Head Uniformity is violated due to some higher-ranked, specific, constraint. Before concluding this section we will take a brief look at some more complex examples from the nominal domain, spanning more than one extended projection, where the Head-Proximate Filter also comes into play.

We consider Greek and Russian, and then Germanic languages. In Greek and Russian the determiner occurs initially in its projection, while the noun follows its adjectival dependent. Since D differs in direction of headedness from the lexical head of its extended projection (the noun), the constraints D-Initial and N-Final (applying to the domain of the noun and its adjectival 
dependent) must both dominate Head Uniformity, as shown in the tableau in (5I)-(52). In addition, N-Final must dominate the Head-Proximate Filter. ${ }^{20}$ This is shown by the sub-tableau in (52), where the AP modifying the noun is head-initial, thereby violating the Head-Proximate Filter, since the adjective (the head of the subordinate domain, or dependent) is not linearly contiguous with its superordinate head, the noun.

\begin{tabular}{|c|c|c|c|c|c|}
\hline Greek/Russian & N-FINAL & D-INITIAL & \begin{tabular}{c|} 
HEAD- \\
PROXIMATE
\end{tabular} & $\begin{array}{l}\text { FINAL- } \\
\text { CLAUSE }\end{array}$ & $\begin{array}{c}\text { HEAD } \\
\text { UNIFORMITY }\end{array}$ \\
\hline a. ${ }^{-} \mathrm{D}[\mathrm{A} \mathrm{N}]$ & & & & & * \\
\hline $\begin{array}{ll}\text { b. } & \mathrm{D}[\mathrm{N} \mathrm{A}] \\
\end{array}$ & $* !$ & & & & \\
\hline c. $[\mathrm{A} \mathrm{N}] \mathrm{D}$ & & $* !$ & & & \\
\hline a. $\mathrm{D}[[\mathrm{A} X \mathrm{XP}] \mathrm{N}]$ & & & $*$ & & * \\
\hline b. $\quad \mathrm{D}[\mathrm{N}[\mathrm{A} \mathrm{XP}]]$ & $* !$ & & & & \\
\hline c. $\quad[[\mathrm{A} X \mathrm{XP}] \mathrm{N}] \mathrm{D}$ & & $* !$ & * & & \\
\hline
\end{tabular}

This contrasts with Germanic languages, where again the constraints D-Initial and N-Final must both dominate Head Uniformity, but this time $\mathrm{N}$-Final is ranked below the Head-Proximate Filter. Where the noun is modified by a simple adjective, as in (53) (or indeed by any head-final AP), we have the same results as in Greek and Russian: the higher-ranked D-Initial and N-Final require a violation of Head Uniformity. However, where the noun is modified by a head-initial AP, as in (54), the results are different: in order to obey the undominated Head-Proximate Filter, N-Final must be violated, resulting in a fully harmonic, consistently head-initial structure:

\begin{tabular}{|c|c|c|c|c|c|}
\hline Germanic & $\begin{array}{c}\text { HEAD- } \\
\text { PROXIMATE }\end{array}$ & D-INITIAL & N-FINAL & $\begin{array}{l}\text { Final- } \\
\text { ClaUSE }\end{array}$ & $\begin{array}{c}\text { HEAD } \\
\text { UNIFORMITY }\end{array}$ \\
\hline a. $\mathrm{D}[\mathrm{A} \mathrm{N}]$ & & & & & * \\
\hline b. $\mathrm{D}[\mathrm{N} \mathrm{A}]$ & & & $* !$ & & \\
\hline c. $[\mathrm{A} \mathrm{N}] \mathrm{D}$ & & $* !$ & & & \\
\hline a. $\quad \mathrm{D}[[\mathrm{A} \mathrm{XP}] \mathrm{N}]$ & $* !$ & & & & $*$ \\
\hline b. $\mathrm{D}[\mathrm{N}[\mathrm{A} \mathrm{XP}]]$ & & & * & & \\
\hline c. $\quad[[\mathrm{A} \mathrm{XP}] \mathrm{N}] \mathrm{D}$ & $* !$ & $* !$ & & & \\
\hline
\end{tabular}

\section{Harmony meets disharmony}

In the previous two sections we established firstly a theory of harmony, consisting of a universal ranking of harmonic word order constraints (I3), and secondly a theory of disharmony, allowing divergence from the order

[20] The ranking of D-Initial with respect to N-Final and Head-Proximate in both Greek and Russian and Germanic languages is not important. Since however it is never violated in these languages, I have kept it undominated in the tableaux in (5I)-(54). 
determined by the Harmonic Word Order Ranking by higher-ranked specific ordering constraints within individual languages. We determined that this latter type of constraint cannot apply to linkers, due to their status as semantically vacuous functional heads. We have already seen the effects of this with subordinating complementisers, where only the Harmonic Word Order Ranking applies (Section 2). In this section we return to two further types of linker: syntactically independent relative clause markers and more general linkers in the complex noun phrase. These cases are of particular interest because the lexical head of the relationship marked by the linker and its dependent are of different categories, thereby enabling us to consider the outcome where harmonic and disharmonic structures interact. We will see that, even where the superordinate noun has a specific ordering constraint conflicting with the constraints of the Harmonic Word Order Ranking, irrespective of the ranking of this specific ordering constraint, the linker always obeys the Head-Proximate Filter, hence the generalisation in (2a). The results of this study will not only add empirical support to the theories put forward in Sections 3-4, but also shed some light on the well-observed near parallels between the distribution of relative clauses and complement clauses, and why such parallels fail to be realised completely.

\section{I Relative clause markers}

We begin by considering syntactically independent relative clause markers - whether a complementiser (such as that in English), a general marker of subordination in the NP (such as de in Mandarin Chinese), or a specialised relative clause marker (or relativiser, such as $c o$ in Czech; see Section I above). The data in (55) below (from Dryer 2008d; see also Greenberg I963: 90, Table Io; Hawkins I983 and subsequent work; Lehmann I984; Dryer 1992: 86, 2007: Section 6.I, 2008e; De Vries 2005: I36-I37; Rijkhoff 2002: 307) shows that the distribution of relative clauses displays certain similarities to that of complement clauses to verbs (compare (I4) above):

(55) (a) Postnominal and $\mathrm{VO}[\mathrm{N}[\mathrm{RC} \mathrm{V}$ O]] 370 languages (64\%)

(b) Prenominal and $\mathrm{OV}\left[\left[\mathrm{RC}_{\mathrm{C}} \mathrm{O} \mathrm{V}\right] \mathrm{N}\right]$ III languages ( $\left.19 \%\right)$

(c) Postnominal and $\mathrm{OV}\left[\mathrm{N}\left[\mathrm{RC}_{\mathrm{C}} \mathrm{O} \mathrm{V}\right]\right] 95$ languages $(\mathrm{I} 6 \%)$

(d) Prenominal and VO $\left[\left[_{\mathrm{RC}} \mathrm{V}\right.\right.$ O]N] 5 languages $(\mathrm{I} \%)$ ( $\mathrm{\%} \%$ of $\mathrm{VO} \operatorname{lgs})$

In OV languages, relative clauses are distributed relatively evenly between prenominal and postnominal position. This mirrors the distribution of complement clauses in relation to the verb in this same set of languages. 
In VO languages, on the other hand, there is a strongly marked preference for relative clauses to follow the noun. While this preference again seems to run parallel to the distribution of complement clauses in VO languages, there is an important difference. In the case of complement clauses, we are dealing with a strict requirement: preverbal complement clauses in these languages are ungrammatical. With relative clauses, on the other hand, we are dealing with a simple statistical preference: prenominal relative clauses in VO languages are possible, but rare.

A final observation concerning the complementiser data in (I4) also applies to relative clause markers: as shown by data in Lehmann (I984), and confirmed as a universal by De Vries (2005: I48; see also Hawkins I994: Section 5; De Vries 2002: 37), syntactically independent relative clause markers always intervene linearly between the head noun and the relative clause they introduce, exactly as predicted by the generalisation in (2a). This therefore gives us the following typological distribution of syntactically independent relative clause markers:

VO languages
N[REL VO]
[VO REL]N (rare)
*N[VO REL]
*[REL VO]N

OV languages
N[REL OV]
[OV REL]N
*N[OV REL $]$
*[REL OV]N

OV languages [OV REL]N *N[OV REL]

We saw in Section 2 that the crosslinguistic distribution of complementisers and the complement clauses they head is exactly captured by the Harmonic Word Order Ranking (I3), both in terms of attested distribution and its relative frequency. This section will show that, despite a small, but significant, difference, the attested distribution of relative clause markers and the relative clauses they head is again precisely predicted by the theories put forward here: not by the Harmonic Word Order Ranking alone, but in combination with the theory of disharmony proposed in Section 3 .

We begin by considering the more simple case of OV languages. The relative clause marker, as a linker, cannot have its own ordering constraints and therefore must obey the Harmonic Word Order Ranking. This can be seen in (57), where the attested orders for OV languages are precisely those predicted by this ranking. Moreover, the relative frequency of the two orders is predicted: since neither is more marked than the other, both appear with near equal frequency (see (55))

\begin{tabular}{|l||c|c:c|}
\hline OV language & HEAD-PROXIMATE & FINAL-ClAUSE & HEAD UNIFORMITY \\
\hline a. $\mathrm{N}[\mathrm{REL} \mathrm{OV}]$ & & & $*$ \\
\hline b. $[\mathrm{OV}$ REL $] \mathrm{N}$ & & $*$ & \\
\hline c. N[OV REL $]$ & $* !$ & & $*$ \\
\hline d. $\quad[$ REL OV]N & $* !$ & $*$ & \\
\hline
\end{tabular}


Turning now to VO languages, it may seem initially as if, like complement clauses (see (I5) above), the Harmonic Word Order Ranking allows only one optimal order, the consistently head-initial order:

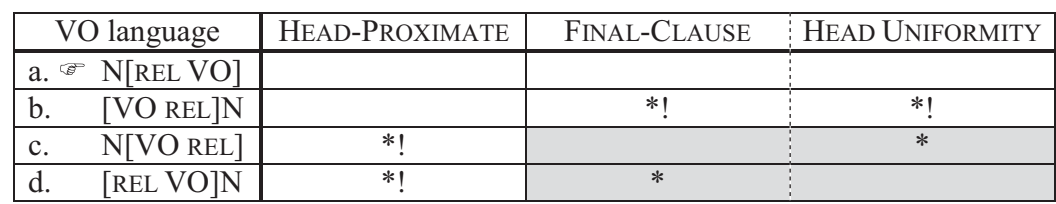

However, recall that while the only constraints that can apply to linkers are those making up the Harmonic Word Order Ranking, this is not necessarily the case with lexical heads. These may have their own ordering rules, requiring them to appear initially or finally within any level of their projection. In the case of relative clauses, the phrase headed by the linker is immediately dominated by a projection of the noun. We must therefore also consider the results where the constraints N-Initial and N-Final applying to this (partial) projection of the noun are introduced into the ranking.

We find very similar results to those discussed in the previous section for the constraints Neg-Initial and Neg-Final. Due to Final-Clause and Head Uniformity, the optimal order for relative clauses in VO languages determined by the Harmonic Word Order Ranking alone requires the noun to appear in initial position. The constraint N-Initial (applying at least to the level of projection of $\mathrm{N}$ encompassing the relative clause) calls for the same result. However, it is possible for the noun to appear in final position if all three constraints - Final-Clause, Head Uniformity and N-Initial-are dominated by N-Final, as in the tableau in (59).

\begin{tabular}{|c|c|c|c|c|c|}
\hline VO language & $\begin{array}{c}\text { HEAD- } \\
\text { PROXIMATE }\end{array}$ & N-FINAL & $\begin{array}{l}\text { FINAL- } \\
\text { CLAUSE }\end{array}$ & $\begin{array}{c}\text { HEAD } \\
\text { UNIFORMITY }\end{array}$ & N-INITIAL \\
\hline $\mathrm{N}$ [REL VO] & & $* !$ & & & \\
\hline b. [VO REL $] N$ & & & * & * & $*$ \\
\hline c. $\quad \mathrm{N}[\mathrm{VO}$ REL] & $* !$ & $* !$ & & $*$ & \\
\hline $\begin{array}{ll}\text { d. } & \text { REL VO]N }\end{array}$ & $* !$ & & $*$ & & * \\
\hline
\end{tabular}

Because of the high ranking of N-Final, candidates (59a) and (59c) are immediately ruled out, and a violation of both Final-Clause and N-Initial is inevitable. The Head-Proximate Filter ensures that candidate (59b), [[VO REL]N], is chosen, also incurring a violation of Head Uniformity. On the other hand, if any one of Final-Clause, Head Uniformity or N-Initial is ranked either equally with, or higher than, N-Final, the (a) candidate, [N[REL VO]] will be optimal. Therefore of the twenty-eight logically possible rankings of N-Initial, N-Final and the constraints of the Harmonic Word Order Ranking, only nine lead to [N[REL VO]] as the optimal order. This explains, firstly, why there are two possible orders for relative clauses in VO languages, 
and, secondly, gives some indication why [[VO REL]N] is much rarer: there are fewer possible rankings leading to this as the optimal order.

As regards OV languages, the Harmonic Word Order Ranking in any case allows one $\mathrm{N}$-initial order, one $\mathrm{N}$-final order (see (57)). Therefore the former will be chosen wherever N-Initial dominates N-Final, and the latter where $\mathrm{N}$-Final dominates N-Initial. Where both constraints are equally ranked, either order will be possible.

Consider now why a parallel situation does not arise with clausal complements of verbs - that is, why we do not find complement clauses in preverbal position in VO languages. The situation where a clausal dependent in a VO language precedes its superordinate lexical head (thereby violating both Head Uniformity and the Final-Clause requirement) will only arise if the superordinate lexical head has a final ordering constraint applying to the domain of projection encompassing the superordinate head and its clausal dependent, this constraint being ranked sufficiently high to be active in determining the winning candidate. In the case of clausal complements of verbs, the superordinate head in question is $\mathrm{V}$; the domain of the clausal dependent is the domain of complements, encompassing both clausal and nominal complements. In a VO language, however, it is simply impossible to have an active $\mathrm{V}$-final ordering constraint applying to the domain of the verb and its complement; if there is an active V-final constraint of this kind, the language as a whole is necessarily $\mathrm{OV} .{ }^{21}$

Returning now to the order [[VO REL]N], the explanation offered above makes a very precise prediction. The languages exhibiting this order should be exactly those VO languages that have an active $\mathrm{N}$-final constraint applying at least to the level of projection of $\mathrm{N}$ encompassing relative clauses. That is to say that in these languages we expect $\mathrm{N}$ to be final not only with respect to relative clauses, but also with respect to any other kind of dependent within the domain of the merger of the noun and the relative clause: we expect any dependent that sits lower in the noun phrase than the relative clause to precede the noun in its base-generated position. Typological evidence from Hawkins (1994: 272, Table 5.8) shows that, in languages where an adjective and a relative clause appear on the same side of the noun (either preceding or following), the unmarked order invariably has the adjective intervening between the noun and the relative clause. This strongly suggests that the adjective is universally merged below the relative clause. Another kind of dependent that may be merged below the relative clause in the noun phrase is the possessor, since it is generally assumed that Universal Grammar has two available positions for possessors: one merged low within NP, and one high, in [Spec, DP]. We therefore expect firstly adjectives to precede the

[2I] If V-Final is ranked below the constraints of the Harmonic Word Order Ranking, [V[CVO]] remains the optimal candidate. If V-Final is ranked any higher, the optimal candidate is $[[\mathrm{OVC}] \mathrm{V}]$. No possible ranking gives *[[VOC]V] as the optimal candidate. 
noun in [[VO REL]N] languages, and secondly any low possessor, if present in the language. ${ }^{22}$

The five VO languages listed by Dryer as having postnominal relative clauses are the Chinese languages Mandarin, Cantonese and Hakka, the Tibeto-Burman language Bai and the Central East Formosan language Amis. To this list we can add Pazih (or Pazeh), a North Formosan language (Comrie 2008). In all these languages the prenominal relative clause is marked by an overt linker.

Firstly, the Chinese languages are well known to have a consistently $\mathrm{N}$-final noun phrase, thereby bearing out the prediction (see (6)-(7) above).

Bai is a more complex case. According to Dryer (2008e: Section 4), possessors, like relative clauses, precede the noun, while adjectives may appear on either side. While at first sight the Bai data seems problematic, a more detailed study reveals that, like the Chinese languages, Bai perfectly bears out the prediction concerning VO languages with prenominal relative clauses. Recall from Section 2 that our theories of harmony and disharmony are concerned not with the surface order, but with the base-generated order. Therefore the predicted restriction to prenominal position for dependents of the noun in languages like Chinese, Bai, Amis and Pazih need apply only at the base-generated level. In the case of Bai, there is good evidence for movement of the noun from final position. The surface order is usually A-N-Dem-Num, with N-Dem-Num-A also attested (Dryer 2008e: Section 4). Extensive work by Abels \& Neeleman (2009, 20I2) on the crosslinguistic distribution of these four elements shows that the orders attested in Bai are not possible as base-generated orders; they can be derived only by leftwards movement of (a projection of) the noun from final position. Specifically, the order A-N-Dem-Num is derived by movement of the noun with pied-piping of the adjective, as in (6oa), while the order N-Dem-Num-A would be derived by movement of the noun alone, as in (6ob):

(60) (a) $[\mathrm{A} \mathrm{N}]_{\mathrm{i}}\left[\right.$ Dem Num $\left.t_{\mathrm{i}}\right]$

(b) $\mathrm{N}_{\mathrm{i}}\left[\right.$ Dem Num A $\left.t_{\mathrm{i}}\right]$

Turning to the Formosan languages, Amis has prenominal adjectives, while possessors may appear on either side of the noun, the postnominal position being preferred (Joy Wu, p.c.). The appearance of the possessor following the noun however is not necessarily problematic, depending on whether this possessor is the low possessor, merged below the relative clause, or the high possessor, in [Spec, DP]. If the postnominal possessor in Amis is

[22] This is not a two-way implication. Languages with prenominal adjectives will not necessarily have prenominal relative clauses, since the domain of adjectives within the NP is smaller than the domain of relative clauses. Therefore it is possible to have an active constraint $\mathrm{N}$-Final applying only to the smaller projection of $\mathrm{N}$ covering the domain of adjectives, leaving the order of relative clauses with respect to $\mathrm{N}$ unaffected. 
associated with $\mathrm{D}$, and hence outside the domain of the relative clause, its appearance in final position poses no problem.

In the final language, Pazih, possessors and adjectives both precede the noun (see Li 2000, Li \& Tsuchida 200I). Pazih, then, like the Chinese languages and Bai, supports the proposal that among VO languages, prenominal relative clauses are available only in those languages that have an active $\mathrm{N}$-final constraint applying at least within the domain of relative clauses, while, on the basis of the data available, Amis is at least compatible with this prediction.

We have seen then that the theories of word order put forward in this paper not only successfully derive the attested cross-linguistic distribution of relative clause markers, including the presence of prenominal relative clauses in VO languages, but also place a restriction on exactly which VO languages should allow this option.

Before leaving the relative clause data, it is worth saying something about relative clauses that are marked not by a linker, but by an affix marking subordination. It has sometimes been claimed that, in addition to the orders given in (56), the order [N[OV REL]] is also attested (Hawkins I990: 244, I994: Section 5; Cinque 2005). However, the languages allegedly exhibiting this order - the Pama-Nyungan languages Dyirbal and Kuku Yalanji, Hurrian (Hurro-Urartian), Lushei (or Mizo, Tibeto-Burman) and Sumerian - mark subordination in the relative clause not by means of an independent syntactic head (that is, a linker), but by a suffix on the verb (see Lehmann 1984: 76-78; De Vries 2002: Appendix II). ${ }^{23,24}$ This is demonstrated by the Dyirbal example in (6I):
yibi [yara-ngu [njalnga-ngu woman man-ERG child-ERG
djilwal-na-nu-ru]] bura-n.
Dyirbal
'The man who had kicked the child saw the woman.'

(Dixon 1969: 38, ex. (I2))

Here the verb in the relative clause is marked by a relative suffix, $-\eta n u$, which replaces the tense suffix (Dixon 1969: 37; Lehmann 1984: 73). That it is

[23] Cinque (2005: 58, 80) also claims Kuku Yalanji exhibits the order [V[OVC]]. The 'complementiser' here is the same subordinating suffix as used in the relative clause. As in Dyirbal, further suffixes can be added to this subordinating suffix. See Patz (2002).

[24] Cinque (2005) also cites Slave(y) (Na-Dené), Pech (Paya) and Teribe as examples of languages displaying this order. In the case of Slave the alleged relative clause marker makes a semantic contribution, and hence is not a true linker (see Rice 1989: Section 47.2). Disharmony is therefore predicted to be possible. In Pech, the marker of subordination is transcribed as an affix and also seems to make a semantic constribution (Cinque 2005: 84). I have not been able to find any information on Teribe. Cinque (2005: 60-6I) further gives Tigre (South Semitic) as an example of the order [[REL TP]N], which is also ruled out for true linkers by the Head-Proximate Filter. In this case the alleged relative clause marker - which is not restricted to initial position in the clause - is in fact a marker of definiteness. See Palmer (I96I) and Raz (1983). 
indeed a suffix, rather than a syntactically independent clitic, is evidenced by the fact that the relative marker is followed by the ergative case marker, itself a suffix.

According to Lexical Integrity, affixes in fact should not fall under the restrictions of the Harmonic Word Order Ranking. A number of theories provide evidence suggesting that affixes do not project in the syntax or are otherwise inaccessible to the syntax component (see, among others, Di Sciullo \& Williams 1987; Ackema \& Neeleman 2002, 2004). If an affix does not head its own projection within the extended projection, or is otherwise invisible to the syntax component, it is subject to neither the Head-Proximate Filter nor Head Uniformity. Greater freedom for semantically vacuous affixes than for semantically vacuous heads (linkers) is therefore predicted.

\subsection{Linkers elsewhere in the noun phrase}

We have seen then that the Harmonic Word Order Ranking in (I3), together with the theory of disharmony presented in Section 3, successfully accounts for the distribution of two types of linker: complementisers and relative clause markers. We have seen that for both types of linker, the dominant constraint in the Harmonic Word Order Ranking, the Head-Proximate Filter, remains unviolated, irrespective of the ranking of any specific constraint targeting the lexical features of the superordinate head. At least for these two types of linker then, the generalisation in (2a) holds true. In Section I a third, broader, set of linkers was mentioned: linkers used more generally in the complex noun phrase, the dependent being of any category. Being likewise semantically vacuous functional heads, this set of linkers is also predicted to conform to the Harmonic Word Order Ranking. The only difference here will be that, where the dependent is not clausal, the Final-Clause requirement will not come into play.

The class of linkers in the noun phrase includes the ezafe/izafe(t) in IndoIranian, the associative marker $-a$ in Bantu, as well as purely functional adpositions such as of in English. It also encompasses the syntactically independent relative clause markers we looked at in Section 4.I. In terms of constituency, Philip (2012: Section 2.4; see also Limburg 1985) provides evidence that linkers in the noun phrase always form a constituent with the dependent they introduce; the linker constitutes the highest head in the extended projection of the dependent, in the same way that subordinating complementisers and relative clause markers form the highest heads in the extended projection of the clauses they mark.$^{25}$ In terms of their distribution, the data in (62) below shows that linkers in the noun phrase, like

[25] This is true even of linkers that attach phonologically to the head noun, such as the West Iranian ezafe (Zwart 2006: Section 2.I; Philip 20I2: Section 2.4). This is demonstrated by coordination data from Persian. If the ezafe $-e$ forms a constituent with the dependent, the 
complementisers and relative clause markers, belong to the class of functional heads obeying the generalisation in (2a). ${ }^{26}$
(a) Initial-over-initial [N[LNK XP]]
(b) Final-over-final [[XP LNK $] \mathrm{N}]$
50 languages $(63-64 \%)$
(c) *Initial-over-final
$[\mathrm{N}[\mathrm{XP} \mathrm{LNK}]]$ potentially I language
28 languages $(35-36 \%)$
(d) *Final-over-initial [[LNK XP]N]
$(\mathrm{O}-\mathrm{I} \%)$
o languages

As with relative clause markers (a subset of linkers in the noun phrase), we are dealing here for the most part with a superordinate head-always a noun - and a dependent of differing category. As with relative clauses, therefore, we expect different results depending on the ranking of the constraints N-Initial and N-Final (applying to the domain of the relevant dependent) with respect to the Harmonic Word Order Ranking. Let us consider firstly the results where either $\mathrm{N}$-initial or N-Final dominates at least part of the Harmonic Word Order Ranking. If the dependent marked by the linker differs from the noun in direction of headedness, violations of Head Uniformity will be requisite. We saw in the previous subsection that in VO languages with prenominal relative clauses, such as Mandarin Chinese, N-Final must dominate at least Final-Clause and Head Uniformity. Therefore, where the noun takes a head-initial dependent of any kind within the domain of the N-Final constraint, the linker marking the relationship will necessarily violate Head Uniformity in order to obey the HeadProximate Filter. We saw an example of this in (7) above from Mandarin Chinese, where the noun was modified by a head-initial PP. This is motivated

ungrammaticality of the ezafe on the first conjunct is predicted. On the other hand, if the ezafe forms a constituent with the head noun, this ungrammaticality is unexplained:
(i) $\left[\operatorname{kolāh}\left({ }^{*}=\mathbf{e}\right)\right.$ va lebās $][=\mathbf{e} \quad$ Maryam $] \quad$ Persian hat $=$ LNK and dress $=$ LNK Maryam 'Maryam's hat and dress'

[26] The languages in my sample displaying the order in (62a) include I4 Indo-European languages (Albanian, Balochi, Hawrami, Kurmanji, Sorani, Zazaki, Persian, Tajik, Romanian, Italian, French, English, German, Dutch), 9 Afro-Asiatic languages (Gude, Afade, Goulfey, Lagwan, Mpade, Mser, Mazera, Zina, Nyam), 8 Niger-Congo languages (Kilega, Gikuyu, Kiitharaka, Swahili, Haya, Kinande, Chichewa, Wolof), 5 Austronesian languages (Rotuman, Kiribati, Bali-Vitu, Samoan, Malo), 2 Creole languages (Berbice Dutch Creole, Tok Pisin), 2 Nilo-Saharan languages (Dholuo, Lango), I Kwadi-Khoe language (Khoe), I Penutian language (Tsimshian) and I Tai-Kadai language (Thai). The languages with the order in (62b) include 8 Sino-Tibetan languages (Cantonese, Mandarin, Taiwanese, Newari, Byansi, Burmese, Lahu, Bai), 4 Austronesian languages (Mayrinax Atayal, Isbukun Bunan, Amis, Pazih), 2 Nilo-Saharan languages (Lendu, Koyra Chiini), I Afro-Asiatic language (Dasenech), I Indo-European language (Hindi), I Mayan language (Tzeltal), I Niger-Congo language (Bambara), I Trans-New Guinea language (Amele), Japanese and Korean. The following languages allow both harmonic orders: 4 Austronesian languages (Palauan, Tagalog, Batad Ifugao, Ilocano) and 3 Indo-European languages (Urdu, Gilaki, Mazandarani). The language potentially displaying the order in (62c) is Kanuri (Nilo-Saharan), discussed later in the subsection. 
in (63): as the highest head in the extended projection of the PP dependent, the Head-Proximate Filter requires the linker to be adjacent to the head noun; of the two candidates $(63 a, b)$ meeting this requirement, only (63a) also obeys the undominated N-Final constraint:

\begin{tabular}{|c|c|c|c|c|c|}
\hline $\begin{array}{c}\text { Head-initial } \\
\text { dependent }\end{array}$ & $\begin{array}{c}\text { HEAD- } \\
\text { PROXIMATE }\end{array}$ & N-FINAL & $\begin{array}{l}\text { FINAL- } \\
\text { CLAUSE }\end{array}$ & $\begin{array}{c}\text { HEAD } \\
\text { UNIFORMITY } \\
\end{array}$ & N-INITIAL \\
\hline a. $[\mathrm{P}$ NP LNK $] \mathrm{N}$ & & & & * & * \\
\hline b. $\quad \mathrm{N}[\mathrm{LNK}$ P NP] & & $* !$ & & : & \\
\hline c. $[\mathrm{LNK}$ P NP]N & $* !$ & & & $\vdots$ & $*$ \\
\hline $\begin{array}{ll}\text { d. } & \text { N[P NP LNK] }\end{array}$ & $* !$ & $* !$ & & 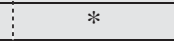 & \\
\hline
\end{tabular}

On the other hand, in a language where the constraints N-Initial and $\mathrm{N}$-Final are ranked below the Harmonic Word Order Ranking, we expect all three constraints in this ranking to be obeyed wherever applicable. An example of such a language is the Malayo-Polynesian language Batad Ifugao. The linker in this language has two allomorphs: an enclitic $-n$, used where the preceding word ends in a vowel, and the independent word an, used immediately following a consonant. Unmodified adjectives precede the noun, with an intervening linker, as in (64a). Where, however, the adjective is modified - a head-initial construction - the AP must follow the noun it modifies, the linker again appearing in intervening position. This is shown in (64b).
(a) nan nappuhi $=\mathbf{n}$ tibung
DET bad $=$ LNK wine.jar
'the bad wine jar'
(b) nan tibung [an nappūhih pan-nig-a']
DET wine.jar LNK bad MANNER-see-ISG
'the wine jar which is bad with reference to the way I see it'

(Dryer 2007: I27, ex. (I75))

The data here can be explained if we assume the following ranking for Batad Ifugao:

\section{(65) Head-Proximate Filter $>>$ Final-Clause, Head Uniformity $>>$ N-FINAL $>>$ N-INITIAL}

The linker must always obey the dominant constraint, the Head-Proximate Filter: therefore it will be final if the dependent is prenominal, and initial if the dependent is postnominal. We firstly consider the case where the noun is modified by a complex head-initial AP, as in (64b), and motivated in the sub-tableau in (66). If the head-initial AP precedes the noun, the linker will be final, so violating Head Uniformity, as in (66b). In order to obey both the Head-Proximate Filter and Head Uniformity, the complex AP follows the noun, the extended projection of which is headed by an initial linker, 
as in (66a). The consequent violation of N-Final is irrelevant, since this constraint is ranked below Head Uniformity. We now turn to the case where the adjectival dependent of the noun is itself unmodified, as in (64a), and motivated in the sub-tableau in (67). In this case Head Uniformity is no longer relevant, since the adjective is non-branching and hence does not have a direction of headedness. Here then, N-Final does come into play: of the two candidates that obey the Head-Proximate Filter, it is the candidate that obeys N-Final, [[A LNK]N], that is optimal.

\begin{tabular}{|c|c|c|c|c|c|}
\hline Batad Ifugao & \begin{tabular}{|c|} 
HEAD- \\
PROXIMATE
\end{tabular} & $\begin{array}{l}\text { FINAL- } \\
\text { CLAUSE }\end{array}$ & $\begin{array}{c}\text { HEAD } \\
\text { UNIFORMITY }\end{array}$ & N-FINAL & N-INITIAL \\
\hline a. $\mathrm{N}[$ LNK A XP] & & & & $*$ & \\
\hline b. $\quad[\mathrm{A}$ XP LNK]N & & & $* !$ & & $*$ \\
\hline c. $[$ LNK A XP]N & $* !$ & & & & $*$ \\
\hline d. $\quad$ N[A XP LNK] & $* !$ & & $*$ & $*$ & \\
\hline a. $[$ A LNK]N & & & & & * \\
\hline b. $\quad \mathrm{N}[\mathrm{LNK} \mathrm{A}]$ & & & & $* !$ & \\
\hline c. $[$ LNK A]N & $* !$ & & & & $*$ \\
\hline $\begin{array}{ll}\text { d. } & \text { N[A LNK] }\end{array}$ & $* !$ & & & * & \\
\hline
\end{tabular}

The above findings therefore confirm those of the previous subsection: where a linker marks the relationship between a superordinate head and a dependent of differing category, we may find otherwise unexpected violations of the Final-Clause requirement and Head Uniformity. Irrespective of the ordering properties of the superordinate head, however, it is predicted that the dominant constraint in the Harmonic Word Order Ranking, the Head-Proximate Filter, will always be obeyed (hence the generalisation in (2a)). With one potential exception, to be discussed below, the results in (62) confirm that this is indeed the case for linkers in the noun phrase.

As with complementisers, there may be surface violations of the HeadProximate Filter. The surface violation poses no problem as long as the linker obeys the Head-Proximate Filter in its base-generated position. I know of two languages displaying such a surface violation. In the first language, Kanuri (Western Saharan), the possessor phrase follows its head noun, and is marked by a genitive case enclitic, $-v e$ (or $-b e$ ). This results in the surface order $[\mathrm{N}[\mathrm{Poss} \mathrm{P}=v e]]$ :

(68) [fátò

$[\mathrm{kâm}$ kúrà $=\mathbf{v e}]]=\mathrm{ga} \quad$ rúskəna.

Kanuri

compound man big $=$ LNK.GEN $=$ OBJ I.saw

'I saw the big man's compound.'

(Dryer 2007: 83, ex. (5I))

The above example demonstrates that -ve is indeed a clitic (and hence a syntactically independent head), as opposed to a suffix: where the possessor is modified, $-v e$ attaches phonologically not to the possessor noun (kâm), but to the final word of the possessor phrase as a whole (kúrà). Being 
a syntactically independent head serving to mark the presence of a relationship, the case clitic is a member of the class of linkers, and therefore predicted to be subject to the Head-Proximate Filter at the base-generated level. In order to maintain exceptionlessly the generalisation in (2a), it would need to be shown that the order given in (68) can only obtain as the result of movement.

Cyffer (I998: 5I) reports that the general ordering of components within the Kanuri noun phrase is as in (69):

(69) N - Possessor phrase - Adjectival - Relative Clause -

Dem/Det - Additive adjunct

While this order itself is not directly indicative of movement, it is not incompatible with it. It is possible that the genitive-marked possessor in fact underlyingly precedes the noun (conforming to the Head-Proximate Filter), and the noun then moves leftwards around the possessor to initial position. Since this potential movement cannot be proven by the data available, however, Kanuri must remain a potential, though not proven, counterexample.

The second language, Pashto, displaying the inverse surface order, provides direct evidence for movement. This language uses the linker de to mark a possessor phrase, exhibiting the surface order [de PossP]N, as shown in (70):

[de Asad] [moţar]
LNK Asad car
'Asad's car'

Pashto

'Asad's car'

(Larson 2009, ex. (56))

Larson (2009) provides evidence suggesting that this word order is the result of movement of the possessor phrase headed by de. His argument is based on the fact that where the relevant extended nominal projection is the complement of a preposition, the linker and possessor precede this preposition, as exemplified in (7I) below. In order to maintain compositional semantics, the possessor must have moved out of the nominal complement of the preposition. Therefore, if, as the data suggests, the base-generated order is [N[de PossP]], Pashto perfectly conforms to the Head-Proximate Filter, and consequently the predicted pattern for linkers.
(a) [de Asad $]_{i}\left[\text { pəo chāqú } t_{i}\right]_{0}$
Pashto LNK Asad with knife 'with Asad's knife'
(b) *pə [de Asad] chāqú with LNK Asad knife

(Larson 2009, ex. (58a))

(Larson 2009, ex. (57a))

We have seen then that the generalisations in (2) are successfully derived by the possible interactions of the Harmonic Word Order Ranking presented in Section 2 with the feature-specific ordering constraints presented in 
Section 3: for linkers, as demonstrated here by complementisers, relative clause markers and linkers in the noun phrase (with the possible exception of Kanuri), the dominant constraint in the Harmonic Word Order Ranking, the Head-Proximate Filter, will always be obeyed at the base-generated level; for any other head, while there is a cross-linguistic preference for harmony, disharmony will always be possible. Moreover, this approach also accounts for certain left-right asymmetries in the cross-linguistic distribution of clausal dependents to verbs and nouns in VO and OV languages, as well as the comparative frequency of distribution. In particular, it makes a very precise prediction about exactly which VO languages should permit prenominal relative clauses. Before concluding our study, we return to the alternative generalisation over disharmonic word orders mentioned in the introduction: FOFC (Final-Over-Final Constraint). I will argue, following Hawkins (20I0), that FOFC is both too weak and too strong, permitting certain unattested orders for linkers, and incorrectly ruling out the final-over-initial order for a number of other heads.

\section{HARMONY, Disharmony, ANd FOFC}

\section{I FOFC and linkers}

We begin by considering the predictions of FOFC as regards the distribution of subordinating complementisers, relative clause markers, and linkers in the noun phrase. FOFC, as formulated in (3) above, predicts that, where the two are categorially non-distinct, a head-final phrase cannot take a head-initial phrase as its complement. This is certainly true of the complementiser data (see (I4) above): VO languages cross-linguistically do not have clause-final complementisers, while OV languages allow both clause-initial and clausefinal complementisers. This is precisely the prediction made by FOFC, irrespective of the headedness of intervening heads, as has been widely documented in the FOFC literature (Biberauer et al. 2007 and subsequent work): either the head-final CP itself immediately dominates an initial TP, as in (72a), or a head-final TP (or some other intermediate projection) immediately dominates the initial VP, as in (72b). Both configurations are ruled out by FOFC: the ungrammatical orders *[V[VOC] $]$ and *[[VOC]V] are therefore ruled out.

(72) (a) $[[\mathrm{T} V \mathrm{VP}] \mathrm{C}]$

(b) $[[\mathrm{VO} \mathrm{T}] \mathrm{C}]$

Section 2 highlighted a second curiosity in the data: although OV languages allow clause-initial complementisers, a clause headed by such a complementiser must always appear in postverbal position, never in canonical object position. This requirement is also captured by FOFC as it is formulated in (3). According to this formulation, the domain of FOFC 
extends across both clauses since both allegedly form a single extended projection: matrix $\mathrm{V}$ and $\mathrm{C}$ both bear the feature $[+\mathrm{V}]$, such that $\mathrm{CP}$ is a categorially non-distinct complement of V. As pointed out by Sheehan (2008: 2, I4), Biberauer et al. (2009: Section 5.I) and Biberauer \& Sheehan (2010), it is therefore predicted that a complementiser-initial CP cannot be dominated by a head-final VP. Therefore complementiser-initial clauses are only possible postverbally, ruling out the ungrammatical orders * $[[\mathrm{CVO}] \mathrm{V}]$ and *[COV]V]. Note however that this explanation comes at some theoretical cost. In order to include this data within the explanatory scope of FOFC, Biberauer et al. (2010) are forced to add a stipulation to Grimshaw's (I99I, 2005) notion of extended projection, allowing an extended projection to include the complement of its lexical head, as long as the two are categorially non-distinct. This added stipulation has serious consequences. Grimshaw (I99I, 2005) provides a wealth of convincing evidence that features within an extended projection cannot contradict each other. This however is not the case between matrix and complement clauses: for example, in the Malayalam and Bengali examples in (I7) and (2I), the two clauses have different tenses, while in the Persian example in (I8) they differ in aspect. If the definition of extended projection is to be extended in the manner Biberauer, Holmberg and Roberts suggest, the claim that features within an extended projection cannot contradict will therefore have to be given up, thereby losing much of the explanatory power of the original notion of extended projection.

This leaves one more unattested order: *[V[OVC]]. FOFC does not provide a direct explanation for the ungrammaticality of this order (see Hawkins 20IO). Biberauer \& Sheehan (20I0: 5I) however posit that the absence of this order can be explained indirectly by FOFC: if complement clauses in OV languages appear in postverbal position purely to avoid violating FOFC, there is no reason for a clause that would not otherwise violate FOFC in preverbal position to appear in this postverbal position. This explanation is therefore dependent on the assumption that the process resulting in postverbal complement clauses in OV languages is a more costly operation than that used for preverbal ones. However, we have already seen in Section 2 that in both cases the complement clause is base-generated; neither operation is more costly than the other. Therefore attributing the grammaticality of $[[\mathrm{OVC}] \mathrm{V}]$ versus the ungrammaticality of $*[\mathrm{~V}[\mathrm{OVC}]]$ to economy seems dubious. $^{27}$

On the face of it, then, it seems that FOFC, like the Harmonic Word Order Ranking, successfully allows the grammatical orders in (I4), and unequivocally rules out at least the majority of the ungrammatical orders. When we

[27] Indeed, under an LCA-based analysis such as that adopted by Biberauer et al., all complement clauses must be base-generated in postverbal position, and can only appear in preverbal position due to movement. 
look at the data in more detail, however, the situation is not quite so simple. The explanation for the absence of final complementisers in VO languages is based on the assumption that FOFC holds over all heads in the extended verbal projection. The typology in (I4) shows that FOFC always holds as a descriptive observation regarding the order of the complementiser relative to the verb it c-commands. However, examples such as the following from Canela-Krahô show that FOFC does not necessarily hold between CP and TP: here a CP with a final complementiser $n a$ immediately dominates a TP with an initial tense-head, te. Canela-Krahô thereby instantiates the order in (72a), predicted by FOFC to be ungrammatical:

$$
\begin{aligned}
& \mathrm{i}=\text { te }[\mathrm{a}=\text { te ihmutri, capi jũrkwa ri, } \mathrm{a}=\mathrm{kra} \text { cahhyr } \\
& \mathrm{I}=\text { PST } 2=\text { PST there Capi house at } 2=\text { child beat } \\
& \text { na }] \mathrm{a}=\text { pupun. } \\
& \text { LNK } 2=\text { see } \\
& \text { 'I saw you beat your child there, at Capioh } \\
&
\end{aligned}
$$

(Popjes \& Popjes 1986: I38, ex. (73))

On the other hand, the theories of word order put forward in this paper can account for the Canela-Krahô data by assuming the constraint T-Initial

\begin{tabular}{|c|c|c|c|c|c|}
\hline Canela-Krahô & $\begin{array}{c}\text { HEAD- } \\
\text { PROXIMATE }\end{array}$ & T-INITIAL & V-FINAL & $\begin{array}{c}\text { FinAL- } \\
\text { Clause }\end{array}$ & \begin{tabular}{|c|c} 
HEAD \\
UNIFORMITY \\
\end{tabular} \\
\hline a. $[$ TOVC]V & & & & * & * \\
\hline b. $\quad \mathrm{V}[\mathrm{CTOV}]$ & & & $* !$ & & $* *$ \\
\hline $\begin{array}{ll}\text { c. } & {[\mathrm{OVTC}] \mathrm{V}}\end{array}$ & & $* !$ & & $*$ & \\
\hline d. V[TOVC] & $* !$ & & $*$ & & $*$ \\
\hline
\end{tabular}
is undominated, as in (74). In order to obey T-initial, the optimal candidate violates the lower-ranked Head Uniformity, since $\mathrm{T}$ and $\mathrm{V}$ differ in direction of headedness. ${ }^{28}$ The constraint T-Initial is available since the head $\mathrm{T}$ has syntactic features referring to semantics:

The order in (72b), on the other hand, does indeed seem to be ungrammatical (see (I4)). Here the FOFC violation is incurred not by C, but by $\mathrm{T}$. However, we have already seen evidence in Section 3 from the typology in (28) and the data in (39) suggesting that, contrary to previous claims, T and other intermediate heads in the extended verbal projection by no means always comply with FOFC; the order [[VO]T] certainly seems to exist. The explanation for the absence of the order *[VOC], where there are intermediate functional heads, therefore cannot lie with FOFC.

[28] Here I have included the undominated constraint V-Final, to rule out candidate (74b). Alternatively, there is no constraint V-Final, candidates (74a, b) are both equally optimal, but the complementiser $n a$ has a lexical ordering statement requiring it to take its complement to the left. 
Given the empirical facts, then, the grammaticality of the order [[T VP]C] as manifested by Canela-Krahô, and, I would argue, the ungrammaticality of both *[VOC] and *[V[OVC]] all fall outside the explanatory scope of FOFC. Moreover, the presence of the FOFC-violating order [VOC] where C is not a semantically vacuous subordinating complementiser, but a semantically contentful discourse particle, such as an interrogative marker, as in (29) and (49), remains problematic (see Section 5.2 below for further discussion). On the other hand, the account proposed in this paper not only successfully derives both the attested and unattested orders for semantically vacuous subordinating complementisers, as well as their frequency of occurrence, but also permits the disharmonic order [VOC] wherever $\mathrm{C}$ is semantically contentful.

While FOFC at least partially accounts for the complementiser data, the data for relative clause markers and more general linkers in the noun phrase as studied in the previous section falls outside the scope of FOFC, since both disharmonic orders are absent, and not just the final-over-initial order (see also Hawkins 20I0). Given the provisos in the most recent formulation of FOFC, as in (3), even the ungrammaticality of the final-over-initial order $(*[[\mathrm{REL} T \mathrm{TP}] \mathrm{N}]$ and $*[[\mathrm{LNK} \mathrm{XP}] \mathrm{N}])$ in $\left({ }^{6} 6\right)$ and $(62)$ is not predicted by FOFC, since the relative clause and the majority of other dependents introduced by linkers in the noun phrase are adjuncts, not complements, and are arguably of different category. More seriously, FOFC appears to rule out certain attested orders: under FOFC instances of the order [[VO REL $] \mathrm{N}]$ and [[P NP $\mathrm{LNK}] \mathrm{N}]$ are counterexamples that require explanation, since a head-final linker phrase dominates an initial VP or PP. ${ }^{29}$ See examples in (7) above and (75)-(76):

(75)

[zuotian chi yurou de] ren yesterday eat fish LNK person 'the people who ate fish yesterday'
Mandarin Chinese

(Paul to appear, ex. (8a))

[29] 29 According to Simpson's (200I, 2002) analysis, de is a determiner taking the relative clause in its specifier. In this case, since $d e$ and the relative clause would be of differing category, with the relative clause in a specifier position, FOFC would not apply (see (3)). Coordination data, however, provides evidence that $d e$ forms a constituent not with the head noun, as predicted by Simpson's analysis, but with the relative clause, or other dependent introduced by de (Aoun \& Li 2003: 250; see also Philip 20I2: Section 2.4 for further evidence). This supports the view that de is the highest functional head in the extended projection of this dependent and hence is subject to FOFC:

(i) [ [zhuyao de] erqie [women yijing taolun guo de] $]$ important LNK and we already discuss EXP LNK shiqing

Mandarin Chinese matter

'the main matters that we have discussed' 


\subsection{FOFC elsewhere}

We have seen that in terms of linkers, FOFC cannot capture the full range of unattested orders, and in a few cases disallows grammatical orders. As regards non-linkers, FOFC again cannot fully capture the data. It is predicted that a head-final phrase cannot take a categorially non-distinct headinitial phrase as its complement. However, the data we studied in Section 3 (see (28)-(30), (38), (39), (4I), (43) and (49)) suggests that this prediction is too strong; the final-over-initial order is cross-linguistically dispreferred, but not ungrammatical. Moreover, in general the FOFC-violating final-overinitial order, where head and complement are categorially non-distinct, does not seem to be any rarer than other disharmonic orders permitted by FOFC: either the initial-over-final order, as in the (c) examples in (28)-(33), or the final-over-initial order where head and complement are categorially distinct, as in (3I)-(33) (see Hawkins 20I0).

In Section 3 we looked in some detail at the presence of disharmony for tense, aspect, negative and interrogative markers. As predicted by the theory of specific constraints targeting heads with syntactic features encoding semantics, we found evidence for both initial-over-final and final-over-initial structures. For FOFC, however, these final-over-initial structures are counterexamples that require explanation. Here we will take a brief look the explanation of the counterexamples offered by Biberauer et al. (2010), and why, at the very least in the case of the Lagwan data, it appears to be inadequate.

In the case of final tense and aspect markers in VO languages, Biberauer et al. (2007 and subsequent work) propose that a distinction should be made between uninflected particles and inflected auxiliaries. They claim that, while the order [[VO]T/Asp] is widely attested for the former, it is strikingly absent where the tense/aspect marker is an inflected auxiliary. While the order [[VO]Aux] does largely appear to be absent for inflected auxiliaries (though see Sheehan 2008: 8 and Biberauer et al. 2010: 8-9, fn. 4 for some potential counterexamples), this result is actually not so surprising. It should be noted that for many of the VO languages exhibiting final uninflected tense or aspect particles, there is simply no verbal inflection in the language at all (Matthew Dryer, p.c.). This can be seen in (38)-(39) above, where not only are the final tense and aspect markers uninflected, but also the verb itself and the initial aspect marker. In such a case we would hardly expect inflection to turn up on the final markers. Moreover, even in languages that do display subject agreement, the results are not altogether unexpected, as pointed out by Julien 
(2002: 52-53, fn. 32). Julien suggests that uninflected tense particles are T heads to which the verb has not moved, while inflected auxiliaries are often $\mathrm{V}+\mathrm{T}$ combinations. The latter share the distribution of any other finite verb.

Moreover, in order to exclude uninflected tense and aspect particles from the predictions of FOFC, it would need to be proven that they are not heads in the extended verbal projection. For example, many tense or aspect markers may have semantic (near) equivalents in adverbs. If, however, the final tense and aspect particles were phrasal it would need to be shown: for example, we might expect to see, firstly, evidence for internal structure through the possibility of modification; secondly, possible focus-movement of the particle; thirdly, possible coordination of the particle with another phrase, but not with another head. Moreover, in order for FOFC to hold, the final particle would have to be phrasal in ALL the languages exhibiting the order [[VO]T/Asp].

As regards negative and interrogative markers, Biberauer et al. (20I0: 8I-85) claim that they are syncategorematic; that is, they neither c-select nor are c-selected, and hence are in some sense outside the verb's extended projection. Such an analysis is incompatible with the examples we looked at from Lagwan in (43)-(47) and (49)-(50) above. Firstly, the comparison of the imperative and the prohibitive (see (45) and (46)) strongly suggested that sá, the negative head in Lagwan, must select TP, not VP, and hence is involved in c-selection. Secondly, if an interrogative marker is syncategorematic and cannot be c-selected, it is predicted that it should only be able to appear as the highest head in root questions; it should not appear in subordinate clauses (Biberauer et al. 20I0: 83). However, example (50) above shows directly that the final interrogative marker in Lagwan, $d a$, can indeed appear in subordinate clauses.

Bailey (20IO) and Biberauer et al. (20I0: 8I) also offer an alternative explanation for the presence of final interrogative markers in VO languages. Jayaseelan (2008) and Bailey (2010) point out that in many languages the so-called question particle and disjunctive connective are homophonous. Bailey (20IO) and Biberauer et al. (20I0: 8I) use this to suggest that the apparently final interrogative marker may in fact be an initial disjunctive connective with an elided second conjunct, in a structure of the kind [TP [or TP]] (see Katz I972: Chapter 5; Bencini 2003; Aldridge 20II on Mandarin Chinese). It should be noted, however, that this is not the conclusion Jayaseelan (200I, 2008) draws. (Note, in particular, that in Malayalam, on which Jayaseelan's studies are largely based, the disjunctive connective -oo, although homophonous with the interrogative marker, cannot be used to coordinate tensed clauses, Jayaseelan 200I: 65, fn. I.) In any case, this analysis cannot account for the presence of the final interrogative marker $d a$ in Lagwan. The coordination example in (77) shows that the disjunctive connective is an entirely different morpheme, ndi. That the final interrogative marker in Lagwan is not a disjunctive connective is confirmed by its optional 
Final-Clause requirement, with the Head-Proximate Filter universally taking precedence. Evidence supporting this ranking has been given by various types of linker, in particular complementisers, relative clause markers, and linkers in the complex noun phrase. I have shown that deviation from the optimal order is possible only where specific ordering constraints target either a lexical head or syntactic features encoding semantics. The possible presence or absence of disharmony is therefore directly related to the presence or absence of certain features on a head. The combination of these theories of harmony and disharmony results in the generalisations in (2). These generalisations have been shown to be empirically superior to FOFC, in terms of both what is permitted and what is disallowed. Furthermore, our study has shown that harmony is concerned not with the surface linear order, but with the base-generated, or first-merged, order. This is suggestive that ordering at least to some extent is a product of the narrow syntax, rather than belonging exclusively to PF.

\section{REFERENCES}

Abels, Klaus \& Ad Neeleman. 2009. Universal 20 without the LCA. In Jose M. Brucart, Anna Gavarró \& Jaume Solà (eds.), Merging features: Computation, interpretation and acquisition, 60-79. New York: Oxford University Press.

Abels, Klaus \& Ad Neeleman. 20I2. Linear asymmetries and the LCA. Syntax I5.3, 25-74.

Aboukar, Ousmane Kirna. 2003. Essai de la description de la morphologie nominale de lagwan: dialecte kotoko. MA dissertation, Université de N'Djaména.

Ackema, Peter \& Ad Neeleman. 2002. Syntactic atomicity. Journal of Comparative Germanic Linguistics 6.2, 93-128.

Ackema, Peter \& Ad Neeleman. 2004. Beyond morphology: Interface conditions on word formation. Oxford: Oxford University Press.

Aldridge, Edith. 20Ir. Neg-to-Q: The historical development of one clause-final particle. The Linguistic Review 28.4, 4II-447.

Alrenga, Peter. 2005. A sentential subject asymmetry in English and its implications for complement selection. Syntax 8.3, 175-207.

Aoun, Joseph \& Yen-hui Audrey Li. 2003. Essays on the representational and derivational nature of grammar: The diversity of wh-constructions (Linguistic Inquiry Monograph 40). Cambridge, MA: MIT Press.

Bailey, Laura. 20I0. Sentential word order and the syntax of question particles. Newcastle Working Papers in Linguistics I6, 23-43. http://www.ncl.ac.uk/linguistics/assets/documents/ BAILEY.pdf (accessed 3 August 20I0).

Bartsch, Renate \& Theo Vennemann. 1972. Semantic structures: A study in the relation between semantics and syntax. Frankfurt am Main: Athenäum.

Bayer, Josef. 1996. Directionality and logical form. Dordrecht: Kluwer.

Bayer, Josef. I999. Final complementizers in hybrid languages. Journal of Linguistics 35.2, 233-27I.

Bayer, Josef. 200I. Two grammars in one: Sentential complements and complementizers in Bengali and other South-Asian languages. The Yearbook of South Asian Languages and Linguistics: Tokyo Symposium on South Asian Languages-Contact, Convergence and Typology, II-36. New Delhi: Sage Publications.

Bencini, Giulia. 2003. Toward a diachronic typology of yes/no question constructions with particles. Chicago Linguistics Society (CLS) 39, 604-62I.

Biberauer, Theresa, Anders Holmberg \& Ian Roberts. 2007. Disharmonic word-order systems and the Final-over-Final-Constraint (FOFC). Incontro di Grammatica Generativa (IGG) 33, $86-$ I05. 


\section{JOY PHILIP}

Biberauer, Theresa, Anders Holmberg \& Ian Roberts. 20I0. A syntactic universal and its consequences. Ms., University of Cambridge, Stellenbosch University \& Newcastle University. http://research.ncl.ac.uk/linearization/BHR_20I0.pdf (accessed 27 September 20I0).

Biberauer, Theresa, Glenda Newton \& Michelle Sheehan. 2009. Limiting synchronic and diachronic variation and change: The Final-over-Final Constraint. Language and Linguistics I0.4, 70I-743.

Biberauer, Theresa \& Michelle Sheehan. 20I0. Disharmony, antisymmetry, and the Finalover-Final Constraint. Ms., University of Cambridge, Stellenbosch University \& Newcastle University. http://research.ncl.ac.uk/linearization/Biberauer_Sheehan_WSB_20Io.pdf (accessed 23 April 20I0).

Blackings, Mairi \& Niger Fabb. 2003. A grammar of Ma'di. Berlin: Mouton de Gruyter.

Cain, Bruce D. \& James W. Gair. 2000. Dhivehi (Maldivian). Munich: Lincom Europa.

Carlson, Robert. 1991. Grammaticalization of postpositions and word order in senufo languages. In Elizabeth Closs Traugott \& Bernd Heine (eds.), Approaches to grammaticalization, vol. 2: Focus on types of grammatical markers, 20I-223. Amsterdam: John Benjamins.

Chomsky, Noam. 1981. Lectures on government and binding. Dordrecht: Foris.

Chomsky, Noam. 2005. Three factors in language design. Linguistic Inquiry 36.I, I-22.

Cinque, Guglielmo. 1999. Adverbs and functional heads: A cross-linguistic perspective. New York: Oxford University Press.

Cinque, Guglielmo. 2005. A note on verb/object order and head/relative clause order. University of Venice Working Papers in Linguistics I5, 49-104. http://lear.unive.it/bitstream/ I0278/197/I/2005-2S-Cinque.pdf (accessed 3 November 2009).

Cinque, Guglielmo. 2009. The fundamental left-right asymmetry of natural languages. In Scalise et al. (eds.), I65-I84.

Comrie, Bernard. 2008. Prenominal relative clauses in verb-object languages. Language and Linguistics 9.4, 723-733.

Cyffer, Norbert. 1998. A sketch of Kanuri. Cologne: Rüdiger Köppe.

Deutscher, Guy. 2007. Syntactic change in Akkadian. Oxford: Oxford University Press.

Di Sciullo, Anna Maria \& Edwin Williams. 1987. On the definition of word. Cambridge, MA: MIT Press.

Dikken, Marcel den \& Pornsiri Singhapreecha. 2004. Complex noun phrases and linkers. Syntax 7.I, I-24.

Dixon, R. M. W. 1969. Relative clauses and possessive phrases in two Australian languages. Language 45.I, 35-44.

Dryer, Matthew S. I980. The positional tendencies of sentential noun phrases in Universal Grammar. Canadian Journal of Linguistics 25, I23-195.

Dryer, Matthew S. I988. Universals of negative position. In Michael Hammond, Edith A. Moravcsik \& Jessica R. Wirth (eds.), Studies in syntactic typology, 93-I24. Amsterdam: John Benjamins.

Dryer, Matthew S. 1992. The Greenbergian word order correlations. Language 68.I, 8I-I38.

Dryer, Matthew S. 2007. Word order. In Timothy Shopen (ed.), Language typology and syntactic description, vol. I: Clause structure, 2nd edn., 6I-I3I. Cambridge: Cambridge University Press.

Dryer, Matthew S. 2008a. Order of object and verb. In Haspelmath et al. (eds.), Chapter 83 . http://2008.wals.info/feature/description/83 (accessed 27 July 20II).

Dryer, Matthew S. 2008b. Position of polar question particles. In Haspelmath et al. (eds.), Chapter 92. http://2008. wals.info/feature/description/92 (accessed 27 July 20II).

Dryer, Matthew S. 2008c. Relationship between the order of object and verb and the order of adposition and noun phrase. In Haspelmath et al. (eds.), Chapter 95. http://2008.wals.info/ feature/95 (accessed 27 July 201I).

Dryer, Matthew S. 2008d. Relationship between the order of object and verb and the order of relative clause and noun. In Haspelmath et al. (eds.), Chapter 96. http://2008.wals.info/ feature/96 (accessed 27 July 20II).

Dryer, Matthew S. 2008e. Word order in Tibeto-Burman languages. Linguistics of the TibetoBurman Area 3I.I, I-84.

Dryer, Matthew S. 2009a. The Branching Direction Theory of word order correlations revisited. In Scalise et al. (eds.), I85-207. 
Dryer, Matthew S. 2009b. Verb-object-negative order in central Africa. In Norbert Cyffer, Erwin Ebermann \& Georg Ziegelmeyer (eds.), Negation patterns in West African languages and beyond, 307-362. Amsterdam: John Benjamins.

Escribano, José Luis González. 2004. Head-final effects and the nature of modification. Journal of Linguistics 40.I, I-43.

Fried, Mirjam. 20I0. Accusative relative pronoun in the Czech relative clauses with absolutive relativizer co. Korpus, gramatika, axiologie I.I, I6-29.

Greenberg, Joseph H. 1963. Some universals of grammar with particular reference to the order of meaningful elements. In Joseph H. Greenberg (ed.), Universals of language, 73-II3. London: MIT Press.

Grimshaw, Jane. 199I. Extended projection. Ms., Brandeis University.

Grimshaw, Jane. 2005. Words and structure. Stanford, CA: Centre for the Study of Language and Information.

Güldemann, Tom. 2006. Structural isoglosses between Khoekhoe and Tuu: The Cape as a linguistic area. In Yaron Matras, April McMahon \& Nigel Vincent (eds.), Linguistic areas: Convergence in historical and typological perspective, 99-134. Basingstoke: Palgrave Macmillan.

Haspelmath, Martin, Matthew S. Dryer, David Gil \& Bernard Comrie (eds.). 2008. World atlas of language structures online. http://2008.wals.info/ (accessed 27 July 20II).

Hawkins, John A. 1983. Word order universals. New York: Academic Press.

Hawkins, John A. I990. A parsing theory of word order universals. Linguistic Inquiry 21.2, 223-26I.

Hawkins, John A. 1994. A performance theory of order and constituency. Cambridge: Cambridge University Press.

Hawkins, John A. 20I0. Disharmonic word orders from a processing typology perspective. Ms., University of Cambridge.

Holmberg, Anders. 2000. Deriving OV order in Finnish. In Peter Svenonius (ed.), The derivation of $V O$ and $O V, \mathrm{I} 23-\mathrm{I} 52$. New York: Oxford University Press.

Jayaseelan, K. A. 200I. Questions and question-word incorporating quantifiers in Malayalam. Syntax 4.2, 63-93.

Jayaseelan, K. A. 2008. Question particles and disjunction. Ms., EFL University, Hyderabad. http://ling.auf.net/lingBuzz/000644 (accessed 3 June 20I0).

Jespersen, Otto. 1917. Negation in English and other languages. Copenhagen: Høst.

Julien, Marit. 2002. Syntactic heads and word formation: A study of verbal inflection. Oxford \& New York: Oxford University Press.

Karimi, Simin. 200I. Persian complex DPs: How mysterious are they? Canadian Journal of Linguistics 46.I-2, 63-96.

Katz, Jerrold J. 1972. Semantic theory. New York: Harper \& Row.

Kayne, Richard S. I992. Italian negative imperatives and clitic-climbing. In Liliane Tasmowsky \& Anne Zribi-Hertz (eds.), Hommages à Nicolas Ruwet, 300-3I2. Gent: Communication and Cognition.

Kayne, Richard S. I994. The antisymmetry of syntax. Cambridge, MA: MIT Press.

Koster, Jan. I978. Why subject sentences don't exist. In Samuel J. Keyser (ed.), Recent transformational studies in European languages, 53-64. Cambridge, MA: MIT Press.

Krishnamurti, Bh. \& J. P. L. Gwynn. 1985. A grammar of modern Telugu. Delhi: Oxford University Press.

Kutsch Lojenga, Constance. 1994. Ngiti: A Central Sudanic language of Zaire. Cologne: Rüdiger Köppe.

Laka, Itziar. 1990. Negation in syntax. Ph.D. dissertation, MIT.

Larson, Richard K. 2009. Chinese as a reverse ezafe language. Yuyanxue Luncong 39, 30-85. Beijing: Peking University Press.

Lehmann, Christian. 1984. Der Relativsatz. Tübingen: Gunter Narr.

Li, Paul Jen-kuei. 2000. Some aspects of Pazeh syntax. Grammatical analysis: Morphology, syntax, and semantics. Studies in honor of Stanley Starosta (Oceanic Linguistics Special Publication 29), 89-I08. Honolulu, HI: University of Hawaii Press.

Li, Paul Jen-kuei \& Shigeru Tsuchida. 200I. Pazih dictionary. Taipei: Institute of Linguistics (Preparatory Office). 


\section{JOY PHILIP}

Limburg, Machiel J. 1985. On the notion "relator" and the expression of the genitive relation. In A. Machtelt Bolkestein, Casper de Groot \& J. Lachlan MacKenzie (eds.), Predicates and terms in Functional Grammar, I47-I63. Dordrecht: Foris.

Mazzon, Gabriella. 2004. A history of English negation. Harlow: Pearson Longman.

Merchant, Jason. 2006. Why no(t)? Style 40.I-2, 20-23.

Ouhalla, Jamal. I99I. Functional categories and parametric variation. London \& New York: Routledge.

Owens, Jonathan. 1985. A grammar of Harar Oromo (Northeastern Ethiopia). Hamburg: Helmut Buske.

Palmer, Frank R. I96I. Relative clauses in Tigre. Word I7.I, 23-33.

Patz, Elisabeth. 2002. A grammar of the Kuku Yalanji language of North Queensland (Pacific Linguistics 527). Canberra: Australian National University.

Paul, Waltraud. 2007. The insubordinate subordinator $d e$ in Mandarin Chinese. Ms, CRLAO, Paris. http://ling.auf.net/lingBuzz/ooIoro (accessed 22 February 20I0).

Paul, Waltraud. To appear. Why particles are not particular: Sentence-final particles in Chinese as heads of a split CP. Studia Linguistica.

Payne, John R. I985. Negation. In Timothy Shopen (ed.), Language typology and syntactic description, vol. I: Clause structure, 197-242. Cambridge: Cambridge University Press.

Philip, Joy. 20I2. Subordinating and coordinating linkers. Ph.D. dissertation, University College London.

Popjes, Jack \& Jo Popjes. 1986. Canela-Krahô. In Desmond C. Derbyshire \& Geoffrey K. Pullum (eds.), Handbook of Amazonian languages, vol. I, I28-199. Berlin: Mouton de Gruyter.

Raz, Shlomo. 1983. Tigre grammar and texts. Malibu: Undena Publications.

Reesink, Ger P. 2002. Clause-final negation: Structure and interpretation. Functions of Language 9.2, 239-268.

Rice, Keren. 1989. A grammar of Slave. Berlin: Mouton de Gruyter.

Rijkhoff, Jan. 1984. The Principle of Head Proximity. MA dissertation, University of Amsterdam.

Rijkhoff, Jan. 1986. Word order universals revisited: The Principle of Head Proximity. Belgian Journal of Linguistics I, 95-I25.

Rijkhoff, Jan. 2002. The noun phrase. Oxford: Oxford University Press.

Rood, David. 1973. Aspects of subordination in Lakhota and Wichita. In Claudia W. Corum, Thomas Cedric Smith-Stark \& Ann Weiser (eds.), You take the high node and I'll take the low node (Chicago Linguistic Society/CLS 9), 7I-78.

Rubin, Edward J. 2002. The structure of modifiers. Ms., University of Utah. http://www.hum.utah.edu/linguistics/Faculty/rubin.htm (accessed II January 2008).

Scalise, Sergio, Elisabetta Magni \& Antonietta Bisetto (eds.). 2009. Universals of language today. Berlin: Springer.

Sheehan, Michelle. 2008. FOFC and phasal complements of V. Handout from FOFC seminar series, Cambridge, I5 February 2008. http://research.ncl.ac.uk/linearization/MS_FOFC_ and phases_Cambridge.pdf (accessed I7 September 2009).

Sheehan, Michelle. 20II. Explaining the Final-over-Final Constraint: Formal and functional approaches. Ms., University of Durham. http://ling.auf.net/lingBuzz/oor263 (accessed 20 May 20II).

Shimizu, Kiyoshi. 1983. The Zing dialect of Mumuye. Hamburg: Buske.

Simpson, Andrew. 200I. Definiteness agreement and the Chinese DP. Language and Linguistics 2.I, I25-I56.

Simpson, Andrew. 2002. On the status of 'modifying' DE and the structure of the Chinese DP. In Sze-Wing Tang \& Chen-Sheng Liu (eds.), On the formal way to Chinese languages. Stanford, CA: Centre for the Study of Language and Information.

Simpson, Andrew \& Tanmoy Bhattacharya. 2003. Obligatory overt wh-movement in a whin-situ language. Linguistic Inquiry 34.I, I27-I42.

de Vries, Mark. 2002. The syntax of relativization. Ph.D. dissertation, University of Amsterdam. [LOT Dissertation Series 53, Utrecht.]

de Vries, Mark. 2005. The fall and rise of universals on relativization. Journal of Universal Language 6.I, I25-I57. http://www.unish.org/unish/DOWN/PDF/Mark_De_Vries.pdf (accessed I8 August 2010).

Stevenson, R. C. I969. Bagirmi grammar. Khartoum: University of Khartoum. 
Williams, Edwin. 1982. Another argument that passive is transformational. Linguistic Inquiry I3.I, I60-I63.

Xu Lin \& Zhao Yansun. 1984. Baiyu Jianzhi. Beijing: Minzu Chubanshe.

Zanuttini, Raffaella. I99I. Syntactic properties of sentential negation: A comparative study of Romance languages. Ph.D. dissertation, University of Pennsylvania.

Zanuttini, Raffaella. I994. Speculations on negative imperatives. Rivista di Linguistica 6.I, 67-89.

Zanuttini, Raffaella. 1996. On the relevance of tense for sentential negation. In Adriana Belletti \& Luigi Rizzi (eds.), Parameters and functional heads: Essays in comparative syntax, I8I-207. Oxford: Oxford University Press.

Zanuttini, Raffaella. 1997. Negation and clausal structure: A comparative study of Romance languages. New York: Oxford University Press.

Zeijlstra, Hedde. 2004. Sentential negation and negative concord. Ph.D. dissertation, University of Amsterdam. [LOT Dissertation Series IOI, Utrecht.]

Zwart, Jan-Wouter. 2006. Complementizer agreement and dependency marking typology. Leiden Working Papers in Linguistics 3.2, 53-72. http://www.let.leidenuniv.nl/pdf/lucl/lwpl/3.2/zwart.pdf (accessed 4 December 2006).

Author's address: Linguistics, University College London, Chandler House,

2 Wakefield Street, London WCIN IPF, UK

j.philip@ucl.ac.uk 